\title{
Prevalência e achados epidemiológicos, anatomopatológicos e imuno-histoquímicos dos tumores hepáticos malignos primários de cães da Região Central do Rio Grande do Sul (1965-2012) ${ }^{1}$
}

\author{
Mariana M. Flores ${ }^{2}$, Ronaldo M. Bianchi ${ }^{3}$, Glaucia D. Kommers ${ }^{4}$, \\ Luiz Francisco Irigoyen ${ }^{4}$, Claudio S.L. Barros ${ }^{4}$ e Rafael A. Fighera ${ }^{4 *}$
}

\begin{abstract}
Flores M.M., Bianchi R.M., Kommers G.D., Irigoyen L.F., Barros C.S.L. \& Fighera R.A. 2013. [Prevalence and epidemiological, pathological and immunohistochemical aspects of primary canine malignant hepatic tumors in Rio Grande do Sul, Brazil (1965-2012).] Prevalência e achados epidemiológicos, anatomopatológicos e imuno-histoquímicos dos tumores hepáticos malignos primários de cães da Região Central do Rio Grande do Sul (1965-2012). Pesquisa Veterinária Brasileira 33(4)497-511. Departamento de Patologia, Universidade Federal de Santa Maria, Av. Roraima 1000, Camobi, Santa Maria, RS 97105-900, Brazil. E-mail: anemiaveterinaria@yahoo.com.br

The prevalence and epidemiological and immunohistochemical aspects of primary hepatic malignant tumors (PHMT) were reviewed in dogs necropsied in a 48-year period (1965-2012). Out of those7,373 dogs, 64 died due to PHMT, which corresponds to $0.9 \%$ of the dogs dying from any cause in the period; $7.8 \%$ of dogs which deaths were caused by tumors in general; and $33.5 \%$ of all dogs dying from hepatic tumors (primary and metastatic). Out of the 64 cases of PHMT, 51 were reviewed histologically and evaluated by immunohistochemistry; they were diagnosed as carcinomas (36 cholangiocarcinomas, 9 hepatocellular carcinomas and one hepatocholangiocarcinoma) and sarcomas (5 hemangiosarcomas). In those dogs in which the age was possible determined, 64.7\% (cholangiocarcinomas) and $77.8 \%$ (hepatocellular carcinomas) were old. At necropsy examination cholangiocarcinomas were characterized mainly by a multinodular pattern (83.3\%) while hepatocellular carcinomas occurred both as massive $(44.4 \%)$ or nodular $(44.4 \%)$ distribution. Extra-hepatic metastasis occurred respectively in $77.8 \%$ and $33.3 \%$ of the cases of cholangiocarcinomas and hepatocellular carcinomas; metastatic cholangiocarcinomas affected mainly the lungs (52.8\%), lymph nodes (50\%) and peritoneum (19.4\%). Ascites $(22.2 \%)$ and icterus $(22.2 \%)$ were observed frequently associated to both tumors. Histologically, most part of the cholangiocarcinomas (86.1\%) and of the hepatocellular carcinomas $(55.6 \%)$ presented respectively a tubular or trabecular type. Immunohistochemistry revealed that the majority (63.9\%) of cholangiocarcinomas was positive for CK7 and none was marked for Hep Par 1. The majority (55.6\%) of the hepatocellular carcinomas revealed positive reaction for Hep Par 1 and none was marked for CK7. The results presented here demonstrated a very high prevalence of PHMT, especially cholangiocarcinomas, in the dog. The necropsy, histological and immunohistochemical findings reported might be useful to help veterinary pathologists in the diagnosis of this common form of cancer in dogs of the Rio Grande do Sul, Brazil.
\end{abstract}

INDEX TERMS: Diseases of dogs, oncology, pathology, hepatic tumors, liver tumors, liver cancer.

\footnotetext{
${ }^{1}$ Recebido em 6 de março de 2013.

Aceito para publicação em 28 de março de 2013.

${ }^{2}$ Programa de Pós-Graduação em Medicina Veterinária, área de concentração em Patologia Veterinária, Centro de Ciências Rurais (CCR), Universidade Federal de Santa Maria (UFSM), Camobi, Santa Maria, RS 97105-900, Brasil.
}

\footnotetext{
${ }^{3}$ Curso de Medicina Veterinária, CCR-UFSM, Santa Maria, RS. Bolsista PIBIC/CNPq/UFSM.

${ }^{4}$ Departamento de Patologia, Centro de Ciências da Saúde, UFSM, Av. Roraima 1000, Santa Maria, RS 97105-900. *Autor para correspondência: anemiaveterinaria@yahoo.com.br
} 
RESUMO.- A prevalência e os aspectos epidemiológicos, anatomopatológicos e imuno-histoquímicos dos tumores hepáticos malignos primários (THMP) em cães foram estudados. De 7.373 cães necropsiados em 48 anos (19652012), 64 morreram de THMP, o que corresponde a 0,9\% do total de cães que morreram por qualquer causa, $7,8 \%$ do total de cães que morreram por tumores em geral e 33,5\% do total de cães que morreram por tumores hepáticos. Desses 64 casos de THMP, 51 foram revistos histologicamente, avaliados imuno-histoquimicamente e reclassificados como carcinomas (colangiocarcinomas [ $\mathrm{n}=36$ ], carcinomas hepatocelulares $[n=9]$ e hepatocolangiocarcinoma $[n=1]$ ) e sarcomas (hemangiossarcomas [n=5]). Dos cães com colangiocarcinomas e carcinomas hepatocelulares em que a idade estava disponível nos protocolos, $64,7 \%$ e $77,8 \%$ eram idosos, respectivamente. Na necropsia, colangiocarcinomas caracterizaram-se principalmente por ocorrerem em um padrão multinodular $(83,3 \%)$, enquanto carcinomas hepatocelulares ocorreram tanto de forma massiva $(44,4 \%)$ quanto nodular $(44,4 \%)$. Metástases extra-hepáticas foram vistas em 77,8\% e 33,3\% dos casos de colangiocarcinomas e carcinomas hepatocelulares, respectivamente, e em relação aos colangiocarcinomas afetaram principalmente pulmões $(52,8 \%)$, linfonodos $(50 \%)$ e peritônio $(19,4 \%)$. Ascite $(22,2 \%)$ e icterícia $(22,2 \%)$ foram achados associados ocasionalmente com ambos os tumores. Na histologia, a maior parte dos colangiocarcinomas $(86,1 \%)$ e dos carcinomas hepatocelulares $(55,6 \%)$ tinha padrão tubular e trabecular, respectivamente. Na imuno-histoquímica, a maioria $(63,9 \%)$ dos colangiocarcinomas demonstrou imunomarcação para CK7 e nenhum imunomarcou para Hep Par 1. A maioria (55,6\%) dos carcinomas hepatocelulares demonstrou imunomarcação para Hep Par 1 e nenhum imunomarcou para CK7. Os resultados aqui apresentados demonstram uma altíssima prevalência de THMP, principalmente colangiocarcinomas, e servem para auxiliar, através dos achados de necropsia, histologia e imuno-histoquímica, patologistas veterinários no diagnóstico dessa tão comum forma de câncer em cães da Região Central do RS, Brasil.

TERMOS DE INDEXAÇÃO: Doenças de cães, oncologia, patologia, tumores hepáticos, tumores de fígado, câncer hepático.

\section{INTRODUÇÃO}

Na rotina do Laboratório de Patologia Veterinária da Universidade Federal de Santa Maria (LPV-UFSM), neoplasmas representam a segunda causa de morte ou razão para eutanásia de cães da Mesorregião do Centro Ocidental Rio-Grandense, popularmente conhecida como Região Central do Rio Grande do Sul (RS), atrás apenas das doenças infecciosas, perfazendo 7,8\% dos casos (Fighera et al. 2008). Quando cães são avaliados por faixa etária, neoplasmas contribuem na morte de 32\% dos idosos (Fighera et al. 2008). Os principais neoplasmas de cães diagnosticados em nossa rotina de necropsia incluem: mamários $(29,9 \%)$, cutâneos $(14,6 \%)$, hepáticos $(10 \%)$, ósseos $(8,1 \%)$ e renais $(3,4 \%)$ (Fighera 2008). Apesar da alta frequência de ocorrência, não há estudos epidemiológicos e anatomopatoló- gicos sobre tumores hepáticos em cães dessa região, como ocorre para tumores cutâneos (Souza et al. 2006), mamários (Oliveira Filho et al. 2010), ósseos (Trost et al. 2012) e renais (Inkelmann et al. 2011).

Neoplasmas hepáticos primários podem emergir de hepatócitos (carcinoma hepatocelular [ou hepatoma]), de células do epitélio biliar (colangiocarcinoma [ou adenocarcinoma biliar]), de células neuroendócrinas (carcinoide) ou de células do estroma (sarcomas) (Head et al. 2003). Nos últimos 40 anos, quase a totalidade dos autores aponta o carcinoma hepatocelular como o tumor hepático maligno primário (THMP) mais comum de cães (Strombeck 1978, Patnaik et al. 1980, Patnaik et al. 1981b, Trigo et al. 1982, Ramos-Vara et al. 2001), entretanto, em nossa rotina, colangiocarcinomas são mais prevalentes (Fighera 2008).

Com base nessa problemática, este trabalho tem como objetivo principal estabelecer a prevalência dos diferentes THMP de cães necropsiados na Região Central do RS, como um primeiro passo para entender o porquê da tão alta frequência de ocorrência desses tumores no nosso meio. Este estudo visa também comparar os aspectos epidemiológicos, anatomopatológicos e imuno-histoquímicos dos casos de colangiocarcinomas e carcinomas hepatocelulares diagnosticados no LPV-UFSM com o que é descrito na literatura, a fim de fornecer subsídios que visam melhor direcionar clínicos e patologistas veterinários no diagnóstico desses tumores.

\section{MATERIAL E MÉTODOS}

Os protocolos de necropsias de cães realizadas entre 1965 e 2012 no LPV-UFSM foram revisados em busca de THMP. 0 método de inclusão dos casos neste estudo foi o diagnóstico definitivo do tumor através de critérios histológicos estabelecidos pela Organização Mundial da Saúde (OMS) para tumores do fígado e do sistema biliar (Ponomarkov \& Machey 1976) e pelo Armed Forces Institute of Pathology (AFIP) para tumores do sistema alimentar (Head et al. 2003) e aplicados durante esse período a partir de consultas a diferentes edições do principal livro-texto de patologia de tumores em animais domésticos (Meuten 2002). Esses diagnósticos foram realizados por oito patologistas veterinários pertencentes ao LPV-UFSM em diferentes períodos de tempo, quatro dos quais são autores deste trabalho (R.A.F., C.S.L.B., G.D.K. e L.F.I.).

Este estudo foi dividido em quatro etapas: (1) separação e exame das fichas de necropsia referentes aos casos de THMP; (2) análise dos dados contidos nas fichas de necropsia; (3) reavaliação histológica dos THMP; e (4) validação dos diagnósticos de THMP com auxílio do perfil imuno-histoquímico.

Os protocolos de necropsia referentes aos casos THMP foram separados e examinados. Foram considerados para este estudo apenas casos em que os tumores que acometeram o fígado foram a causa da morte ou a razão para eutanásia do cão. Desses protocolos de necropsia foram retiradas informações referentes ao sexo, à idade, às raças e aos achados macroscópicos (padrão de distribuição no fígado e presença de metástases). Os cães foram classificados apenas como macho e fêmea, independentemente de serem castrados ou não. Foram ainda divididos em três categorias de idade, conforme publicado anteriormente (Fighera et al. 2008): filhotes (até 1 ano de idade), adultos (de 1 a 9 anos de idade) e idosos (10 anos de idade ou mais). Quanto às raças, os cães foram classificados em sem raça definida (SRD) ou de raça pura 
(RP). Cães mestiços, do cruzamento de duas RP, foram considerados como SRD. Todos os casos incluídos ocorreram no Município de Santa Maria, localizado na Mesorregião do Centro Ocidental Rio-Grandense, popularmente conhecida como Região Central do RS. Para fins de comparação, foram calculados os mesmos dados epidemiológicos (idade, sexo e raça) de toda a população de cães necropsiada no LPV-UFSM nesse mesmo período.

Macroscopicamente, os THMP foram classificados de acordo com sua distribuição em: 1) nodular (incluindo multinodular), 2) massivo e 3) difuso. Carcinomas hepatocelulares foram subdivididos nas três categorias (nodular, massivo e difuso) e colangiocarcinomas em apenas duas (multinodular e massivo). $\mathrm{Na}$ categoria "nodular" foram enquadrados todos os tumores que se apresentaram sob a forma de nódulos, únicos ou múltiplos ("multinodular"), com distribuição aleatória no parênquima hepático. Foram inseridos na categoria "massivo" os tumores que se apresentaram sob a forma de massas, geralmente solitárias, que envolviam, e por vezes substituíam, um lobo hepático. Casos em que esse padrão era acompanhado de invasão do lobo hepático adjacente também foram incluídos nessa categoria. A categoria "difuso" englobou casos em que a tumoração afetava todo ou a maior parte do fígado e ocorria como aumento de volume difuso acompanhado de mudanças na cor e consistência do parênquima afetado. Esses critérios basearam-se naqueles descritos por Cullen \& Popp (2002), Head et al. (2003) e Stalker \& Hayes (2007) para carcinoma hepatocelular e colangiocarcinoma.

Foram reavaliados histologicamente todos os casos em que os blocos de parafina foram encontrados no Arquivo do LPV-UFSM. Casos em que os blocos de parafina não foram encontrados foram excluídos. Os achados histológicos reavaliados incluíram: (1) arranjo celular, (2) padrão estromal (escasso ou abundante), (3) índice mitótico (baixo grau $[\leq 2$ mitoses/cga] ou alto grau $\geq 3 \mathrm{mi}$ toses/cga]), (4) atipia celular, (5) pleomorfismo celular, (6) invasão de vasos linfáticos, (7) necrose, hemorragia e inflamação em meio ao tumor, (8) alterações no parênquima hepático adjacente ao tumor e (9) características de benignidade e malignidade no mesmo tumor.

Os THMP foram classificados de acordo com a classificação histológica descrita por Ponomarkov \& Mackey (1976) e Head et al. (2003) em colangiocarcinomas, carcinomas hepatocelulares, carcinoide ou sarcomas. Com base em publicações mais recentes (Shiga et al. 2001), hepatocolangiocarcinoma foi também considerado. Para colangiocarcinomas, os arranjos celulares incluíram os padrões tubular, sólido e cístico (cistadenocarcinoma biliar); para carcinomas hepatocelulares, os padrões foram trabecular, adenoide e sólido.

A técnica de imuno-histoquímica (IHQ) empregada foi a imunomarcação para hepatócitos em tecidos embebidos em parafina (Hepatocyte Paraffin 1 [Hep Par 1]) e para células do epitélio biliar (citoqueratina 7 [CK7]), conforme protocolo descrito a seguir e baseado em Ramos-Vara et al. (2001). Após a desparafinização e reidratação dos tecidos, foi realizada a recuperação antigênica com proteinase $\mathrm{K}^{5}$ a $25^{\circ} \mathrm{C}$, por 20 minutos para CK7 e cinco minutos para Hep Par 1 . 0 bloqueio das peroxidases e avidinas endógenas foi feito com $\mathrm{H}_{2} \mathrm{O}_{2}$ comercial a $3 \%$ por dois tempos de dez minutos e leite em pó comercial diluído em tampão fosfato salino com detergente Tween 20 (PBST) por 15 minutos, respectivamente. Como anticorpo primário foram utilizados anticorpos monoclonais anti-CK7 ${ }^{6}$ e anti-Hep Par $1^{7}$ humanos produzidos em camundongos, diluídos a 1:40 e 1:80 em PBST, respectivamente, e incubados por 19 horas a $4^{\circ} \mathrm{C}$. 0 anticorpo secundário (polímero) ${ }^{8}$ foi utilizado consecutivamente, incubado a $25^{\circ} \mathrm{C}$ por 30 minutos e marcado através da adição do cromógeno de tetracloreto de 3-3' diaminobenzidina $(\mathrm{DAB})^{9}$ por cinco minutos. As lavagens entre as etapas da técnica foram feitas com solução salina-tris com deter- gente Tween 20 (PBST) em pH 7,6. A contra-coloração foi feita com hematoxilina de Harris ${ }^{10}$. Como controles positivos foram utilizados os hepatócitos e os ductos biliares de áreas não afetadas pelo tumor nas mesmas secções histológicas (controle interno) e cortes de fígado normal de um cão adulto fixado em formol 10\% por aproximadamente oito horas. Como controle negativo, as mesmas secções foram utilizadas, com substituição do anticorpo primário por PBST.

Por fim, foram considerados como carcinomas hepatocelulares todos os THMP que preencheram critérios histológicos reconhecidos internacionalmente e que tiveram ou não suas células neoplásicas imunomarcadas para Hep Par 1, mas não para CK7. Foram considerados como colangiocarcinomas todos os THMP que preencheram critérios histológicos reconhecidos internacionalmente e que tiveram ou não suas células neoplásicas imunomarcadas para CK7, mas não para Hep Par 1. Foram considerados como hepatocolangiocarcinomas todos os THMP que preencheram critérios histológicos reconhecidos internacionalmente (dupla população) e que tiveram suas células neoplásicas imunomarcadas para Hep Par 1 (uma das populações) e que tiveram ou não suas células neoplásicas imunomarcadas para CK7 (outra população). Foram considerados como hemangiossarcomas: 1) todos os casos em que o neoplasma era primário do fígado (por ser solitário [ocorrer apenas no fígado] ou por ser primário com metástases apenas em linfonodos e peritônio); 2) que preencheram critérios histológicos reconhecidos internacionalmente; e 3) que tiveram suas células neoplásicas imunomarcadas para o fator de von Willebrand, conforme previamente publicado por Flores et al. (2012).

A interpretação imuno-histoquímica foi realizada por três (M.M.F., R.A.F. e G.D.K.) patologistas veterinários e quantificada de acordo com a intensidade e número de células imunomarcadas em: 0 (sem marcação), 1 (marcação fraca), 2 (marcação moderada), 3 (marcação intensa) e 4 (marcação muito intensa) conforme o estudo prévio realizado por Ramos-Vara et al. (2001).

\section{RESULTADOS}

Dos 7.373 protocolos de necropsia, $823(11,2 \%)$ correspondiam a tumores. Do total de tumores, em 191 (23,2\%) o fígado estava afetado. Desses 191 casos de tumores que acometeram o fígado, 64 (33,5\%) eram THMP e 127 (66,5\%) eram secundários, sendo 63 (33\%) metástases e $64(33,5 \%)$ multicêntricos. Assim, THMP correspondem a $33,5 \%$ do total de cães que morreram por tumores hepáticos, 7,8\% do total de cães que morreram por tumores em geral e $0,9 \%$ do total de cães que morreram por qualquer causa. Dos 64 THMP, 51 foram reavaliados histologicamente e avaliados através da imuno-histoquímica. Com base nos critérios estabelecidos no material e métodos, 46 tumores foram considerados carcinomas (colangiocarcino-

\footnotetext{
${ }^{5}$ Dako Cytomation S3020 ${ }^{\circledR}$, Dako Cytomation, 6392 Via Real, Carpinteria, CA, USA.

${ }^{6}$ Dako Cytomation M7018 ${ }^{\circledR}$, Dako Cytomation, 6392 Via Real, Carpinteria, CA, USA.

${ }^{7}$ Dako Cytomation M7158 ${ }^{\circledR}$, Dako Cytomation, 6392 Via Real, Carpinteria, CA, USA.

${ }^{8}$ Easy Path EP-12-20502 ${ }^{\circledR}$, Erviegas, Rua Lacedemonia, 268, Jardim Brasil, São Paulo, SP, Brasil.

${ }^{9}$ Dako Cytomation K3468 ${ }^{\circledR}$, Dako Cytomation, 6392 Via Real, Carpinteria, CA, USA.

${ }^{10}$ Easy Path EP-101071 ${ }^{\circledR}$, Erviegas, Rua Lacedemonia, 268, Jardim Brasil, São Paulo, SP, Brasil.
} 
mas $[\mathrm{n}=36]$, carcinomas hepatocelulares $[\mathrm{n}=9]$ e hepatocolangiocarcinoma $[\mathrm{n}=1]$ ) e cinco foram considerados sarcomas (hemangiossarcomas [n=5]). Os resultados referentes aos carcinomas hepáticos (carcinomas hepatocelulares, colangiocarcinomas e hepatocolangiocarcinoma) serão expressos separadamente a seguir. Os resultados referentes aos hemangiossarcomas constam de outra publicação (Flores et al. 2012).

\section{Achados epidemiológicos (população geral)}

Entre 1965 e 2012 foram realizadas 7.373 necropsias de cães no LPV-UFSM. Dessas, 53,1\% correspondiam a machos e $46,9 \%$ a fêmeas. Do total de cães, 35,3\% foram incluídos como filhotes, $49,4 \%$ como adultos e $15,3 \%$ como idosos. Dos cães em que dados sobre raça foram encontrados nos protocolos, 59,3\% tinham raça definida e $40,7 \%$ eram SRD. Para fins de comparação, as raças a seguir correspondiam as seguintes prevalências: Pastor Alemão $(10,8 \%)$, Poodle $(5,4 \%)$, Boxer $(4,3 \%)$, Dachshund $(3,5 \%)$, Rottweiler $(3,3 \%)$, Cocker Spaniel (2,5\%), Collie $(2,3 \%)$, Fila Brasileiro $(1,7 \%)$, Husky Siberiano $(0,8 \%)$, Beagle e São Bernardo $(0,4 \%)$, Border Collie (0,3\%), Old English Sheepdog e Setter Irlandês $(0,2 \%)$.

\section{Achados epidemiológicos (população com colangiocar- cinoma)}

Dos 36 cães com colangiocarcinoma, a idade não estava anotada nos protocolos de dois cães. Dos 34 cães em que a idade constava dos protocolos, $22(64,7 \%)$ foram incluídos como idosos e 12 (35,3\%) como adultos. Dos 36 cães com colangiocarcinoma, 18 (50\%) eram machos e 18 (50 $\%)$ eram fêmeas. Dos 36 cães com colangiocarcinoma, 15 $(41,7 \%)$ eram SRD e $21(58,3 \%)$ eram de RP, principalmente Pastor Alemão (5/36 [13,9\%]), Boxer (4/36 [11,1\%]), Poodle (3/36 [8,3\%]), Fila Brasileiro (2/36 [5,5\%]), mas também várias outras raças (Border Collie, Cocker Spaniel, Dachshund, Husky Siberiano, Rottweiler, São Bernardo e Old English Sheepdog (1/36 [2,8\%]). Dos 36 cães afetados, $16(44,4 \%)$ morreram espontaneamente e $20(55,6 \%)$ foram submetidos à eutanásia.

\section{Achados epidemiológicos (população com carcinoma hepatocelular)}

Dos nove cães com carcinoma hepatocelular, sete $(77,8 \%)$ foram incluídos como idosos e dois $(22,2 \%)$ como adultos. Dos nove cães com carcinoma hepatocelular, quatro $(44,4 \%)$ eram machos e cinco $(55,6 \%)$ eram fêmeas. Dos nove cães com carcinoma hepatocelular, três $(33,3 \%)$ eram SRD e seis $(66,7 \%)$ eram de RP, que incluíam Beagle, Collie, Husky Siberiano, Poodle, Rottweiler e Setter Irlandês $(1 / 9[11,1 \%])$. Dos nove cães afetados, seis $(66,7 \%)$ morreram espontaneamente e três $(33,3 \%)$ foram submetidos à eutanásia.

\section{Achados epidemiológicos (população com hepatoco- langiocarcinoma)}

O único cão diagnosticado com hepatocolangiocarcinoma não tinha idade informada, era fêmea, SRD e morreu espontaneamente.
Achados de necropsia (população com colangiocarcinoma)

Na necropsia $(n=36)$, os colangiocarcinomas se apresentaram principalmente sob a forma multinodular (30/36 [83,3\%]) (Fig.1) e menos frequentemente sob a forma massiva (6/36 [16,7\%]) (Fig.2). Alguns casos (8/36 [22,2\%]) interpretados como multinodulares tinham um lobo completamente substituído por uma massa focalmente extensa. Os tumores descritos como multinodulares caracterizavam-se por: 1) serem múltiplos e aleatórios, 2) afetarem a maioria ou todos os lóbulos hepáticos e 3) variarem de 0,1 a $10 \mathrm{~cm}$ de diâmetro. Frequentemente (19/36 [52,8\%]) foram descritos como brancos ou amarelos, com ocasionais áreas vermelhas $(4 / 36[11,1 \%])$, firmes $(11 / 36[30,6 \%])$, umbilicados (14/36 [38,9\%]) (Fig.3), por vezes com seus centros necrosados e repletos de pus, sangue, muco ou uma mistura desses (alguns referidos pelos patologistas como císticos) $(11 / 36$ [30,6\%]). Os tumores descritos como massivos caracterizavam-se por: 1) serem únicos, 2) afetarem apenas um lobo hepático, principalmente o lobo lateral

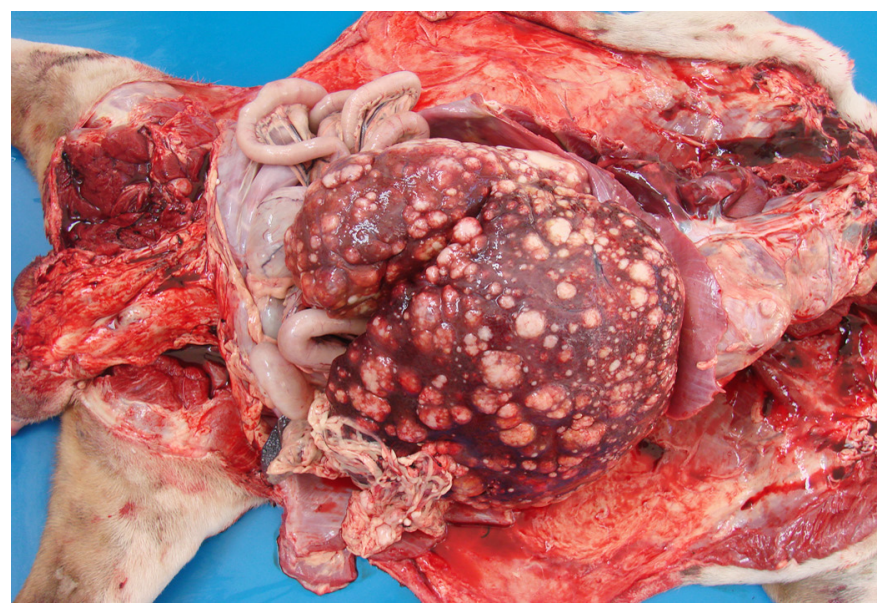

Fig.1. Cadáver, fígado. Marcada hepatomegalia decorrente da infiltração neoplásica na forma de múltiplos nódulos multifocais e coalescentes (padrão multinodular) em um cão com colangiocarcinoma.

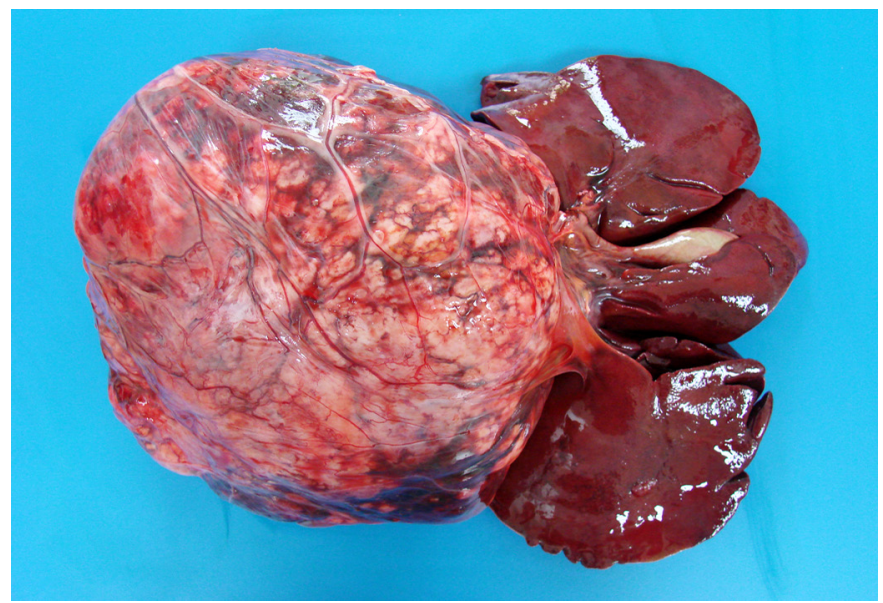

Fig.2. Fígado. Uma grande massa, maior que o próprio fígado, substitui completamente o lobo caudado (padrão massivo) em um cão com colangiocarcinoma. 
esquerdo (2/36 [5,6\%]) e 3) variarem de 8 a $15 \mathrm{~cm} \mathrm{em}$ seu maior eixo. Alguns foram descritos como firmes (6/36 $[16,7 \%])$, brancos ou amarelos, com áreas focais ou multifocais vermelhas (5/36 [13,9\%]) (Fig.4), outros como "císticos" (idênticos aos descritos previamente como um dos padrões multinodulares) (1/36 [2,8\%]) (Fig.5) e outros como borrachentos e homogeneamente pardacentos $[1 / 36$ [2,8\%]) (Fig.6).

Alterações no parênquima adjacente ao tumor não foram comumente descritas nos protocolos, mas nos casos em que se fizeram presentes incluíram: hepatomegalia (7/36 [19,4\%]); alterações na coloração (6/36 [16,7\%]) (que incluíam fígados pálidos $[2 / 36\{5,6 \%\}]$, amarelos $[2 / 36\{5,6 \%\}]$, marrom-amarelados $[1 / 36\{2,8 \%\}]$ ou com áreas brancas, amarelas e vermelhas entremeadas $[1 / 36$ $\{2,8 \%\}])$; aumento da consistência (5/36 [13,9\%]), superfície irregular (5/36 [13,9\%]); e acentuação do padrão lobular $(2 / 36[5,6 \%])$.

Havia metástases extra-hepáticas em 28 dos 36 casos $(77,8 \%)$ de colangiocarcinoma incluídos neste estudo. Os órgãos afetados foram: pulmões (19/36 [52,8\%]), linfonodos (18/36 [50\%]), cavidade abdominal (omento, mesentério e peritônio parietal) $(7 / 36[19,4 \%])$, músculo esquelético (diafragma) (7/36 [19,4\%]), adrenais (5/36 $[13,9 \%])$, baço $(4 / 36$ [11,1\%]), pâncreas $(4 / 36$ [11,1\%]), coração $(3 / 36$ [8,3\%]), rins $(3 / 36[8,3 \%])$, bexiga $(2 / 36$ $[5,6 \%])$, esôfago $(1 / 36[2,8 \%])$, ovário $(1 / 36[2,8 \%])$, ureter $(1 / 36[2,8 \%])$ e músculo esquelético (temporal) $(1 / 36[2,8 \%])$. Além das metástases, outras lesões extra-hepáticas relacionadas ao tumor foram vistas em vários casos $(21 / 36$ [58,3\%]) de colangiocarcinoma e incluíram: hemoperitônio $(8 / 36[22,2 \%])$, icterícia $(8 / 36[22,2 \%])$, ascite $(5 / 36[13,9 \%])$, hidrotórax $(4 / 36[11,1 \%])$, hemotórax $(2 / 36[5,6 \%])$, peritonite $(2 / 36[5,6 \%])$, palidez das mucosas $(1 / 36[2,8 \%])$ e piotórax $(1 / 36[2,8 \%])$.

\section{Achados de necropsia (população com carcinoma he- patocelular)}

Na necropsia ( $n=9)$, os carcinomas hepatocelulares se apresentaram principalmente sob a forma massiva $(4 / 9$
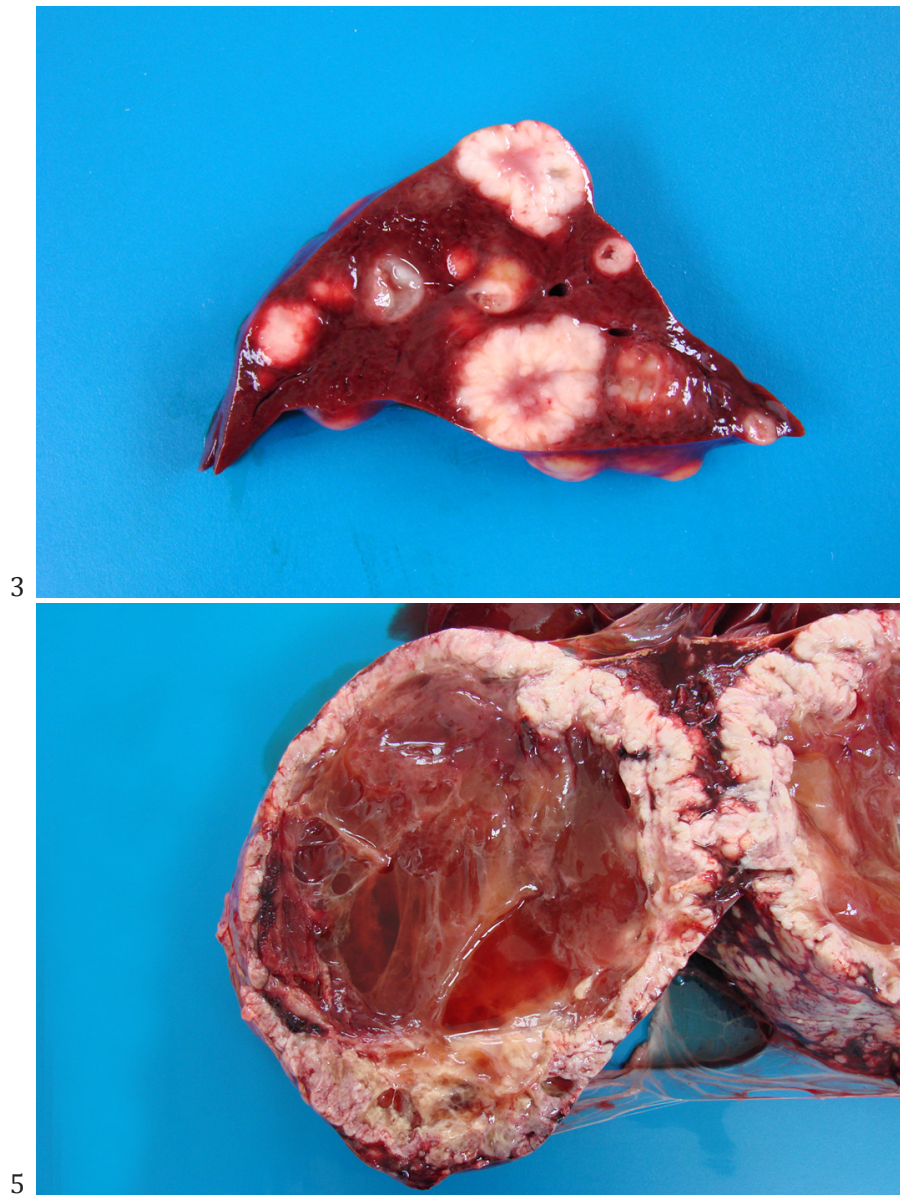

Fig.3. Fígado, superfície de corte. Múltiplos nódulos, alguns dos quais coalescem, brancos, levemente umbilicados e francamente radiados (forma de roseta) estão distribuídos aleatoriamente nesse lobo hepático de um cão com colangiocarcinoma de padrão multinodular.

Fig.5. Fígado, superfície de corte. Um grande "nódulo cístico" repleto de muco misturado com sangue substitui totalmente o tecido hepático afetado em um cão com colangiocarcinoma de padrão massivo.

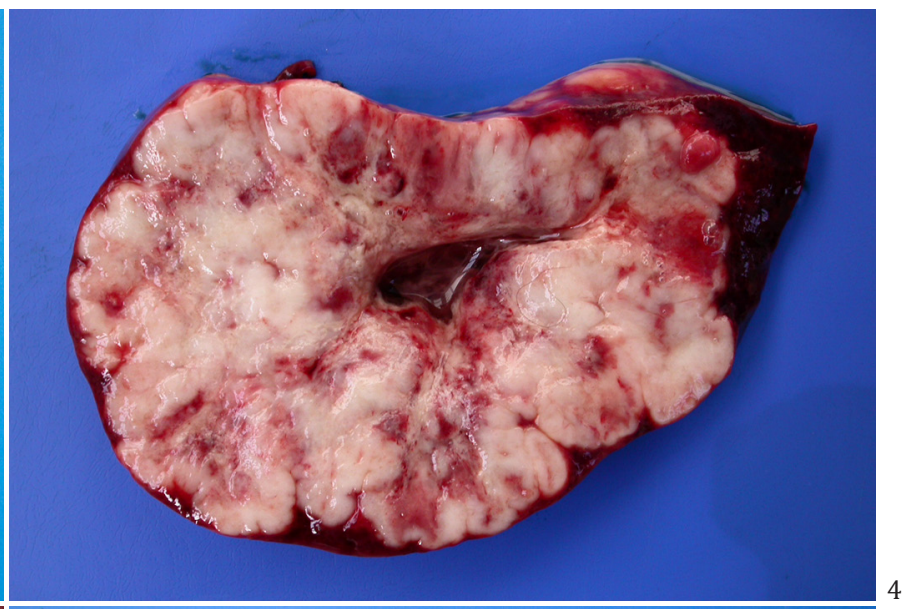

4

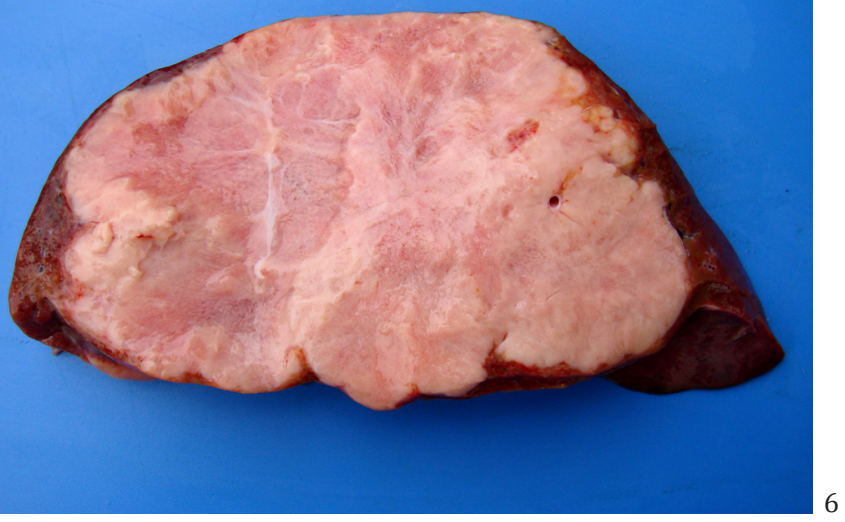

Fig.4. Fígado, superfície de corte. Massa brancacenta única com múltiplas pequenas áreas vermelhas de hemorragia e necrose que substitui completamente o lobo lateral esquerdo em um cão com colangiocarcinoma de padrão massivo.

Fig.6. Fígado, superfície de corte. Massa pardacenta única que substitui parcialmente o lobo lateral esquerdo em um cão com colangiocarcinoma de padrão massivo. Esse "padrão cárneo" de apresentação lembra macroscopicamente um leiomiossarcoma. 

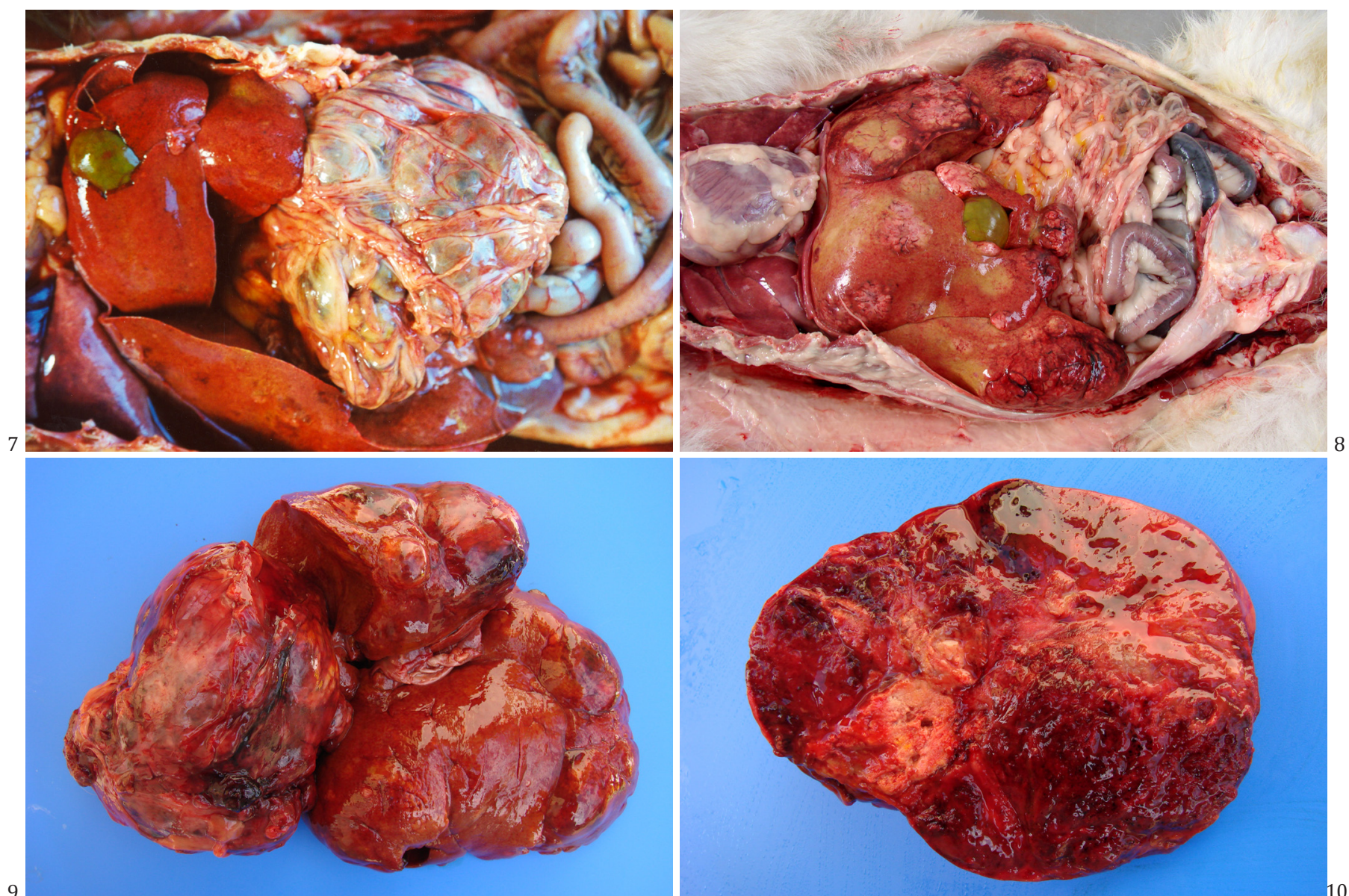

Fig.7. Cadáver, fígado. Uma grande massa, recoberta pelo omento, substitui completamente o lobo lateral esquerdo (padrão massivo) em um cão com carcinoma hepatocelular.

Fig.9. Fígado. Distorção da arquitetura hepática normal em decorrência da infiltração difusa do órgão por células neoplásicas (padrão difuso). Note a marcante irregularidade da superfície natural dos lobos hepáticos.

[44,4\%]) (Fig.7) ou nodular (4/9 [44,4\%]) (Fig.8) e bem menos frequentemente sob a forma difusa $(1 / 9[11,1 \%])$ (Fig.9). Em um caso (1/9 [11,1\%]) interpretado como nodular havia um lobo completamente substituído por uma massa focalmente extensa. Os tumores descritos como massivos caracterizavam-se por: 1) serem únicos, 2) afetarem apenas um lóbulo hepático, principalmente o lobo lateral esquerdo (3/9 [33,3\%]) e 3) variarem de 8 a $18 \mathrm{~cm}$ em seu maior eixo. Foram descritos como brancos ou amarelos (3/9 [33,3\%]), vermelhos (2/9 [22,2\%]) (Fig.10) ou marrom-esverdeados $(1 / 9[11,1 \%])$. A consistência variou de firme $(2 / 9$ [22,2\%]) a macia $(1 / 9$ [11,1\%]) e alguns foram descritos como friáveis $(2 / 9$ [22,2\%]) ou com cavitações repletas de pus $(2 / 9$ [22,2\%]). Os tumores descritos como nodulares caracterizavam-se por: 1) serem múltiplos e aleatórios, 2) afetarem vários ou todos os lobos hepáticos e 3) variarem de 1 a 2,5 cm de diâmetro. Frequentemente foram descritos como brancos ou amarelos $(3 / 9$ [33,3\%]). Apenas um carcinoma hepatocelular foi descrito como difuso; neste caso, o fígado acometido estava aumentado de

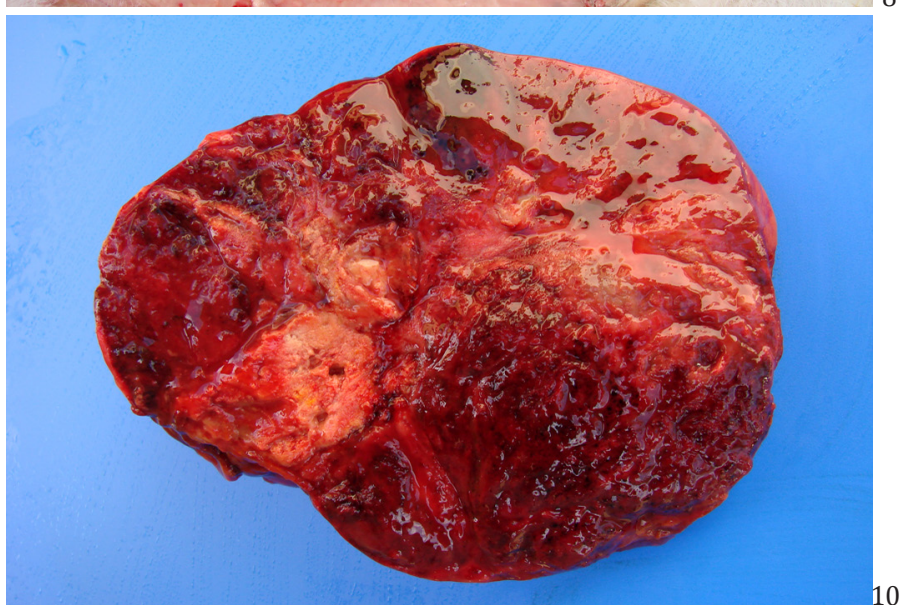

Fig.8. Cadáver, fígado. Marcada hepatomegalia decorrente da infiltração neoplásica na forma de múltiplos nódulos multifocais (padrão nodular) em um cão com carcinoma hepatocelular. Note o amarelamento difuso do órgão decorrente da deposição de gordura (lipidose hepática).

Fig.10. Fígado, superfície de corte. Massa intensamente vermelha e friável com área focalmente extensa mais clara (necrose) que substitui completamente o lobo hepático medial direito de um cão com carcinoma hepatocelular de padrão massivo.

volume, era friável e tinha áreas brancas, amarelas e vermelhas entremeadas.

Alterações no parênquima adjacente ao tumor não foram comumente descritas nos protocolos, mas nos casos em que se fizeram presentes incluíram: hepatomegalia (2/9 [22,2\%]); alterações na coloração (fígado "cor de tijolo") (1/9 [11,1\%]); e acentuação do padrão lobular $(1 / 9$ [11,1\%]). Havia metástases extra-hepáticas em três dos nove $(33,3 \%)$ casos de carcinoma hepatocelular incluídos neste estudo. Os órgãos afetados foram: pâncreas $(2 / 9[22,2 \%])$, linfonodos regionais $(2 / 9[22,2 \%])$ e pulmões $(1 / 9[11,1 \%])$. Assim como as metástases, outras lesões extra-hepáticas relacionadas ao carcinoma hepatocelular foram vistas apenas incomumente $(4 / 9$ [44,4\%]) e incluíram: hemoperitônio (2/9 [22,2\%]), icterícia $(2 / 9[22,2 \%])$ e palidez das mucosas $(2 / 9[22,2 \%])$.

\section{Achados de necropsia (população com hepatocolangio- carcinoma)}

Na necropsia $(n=1)$, o hepatocolangiocarcinoma ocorreu como uma massa multilobulada única (forma massiva), 


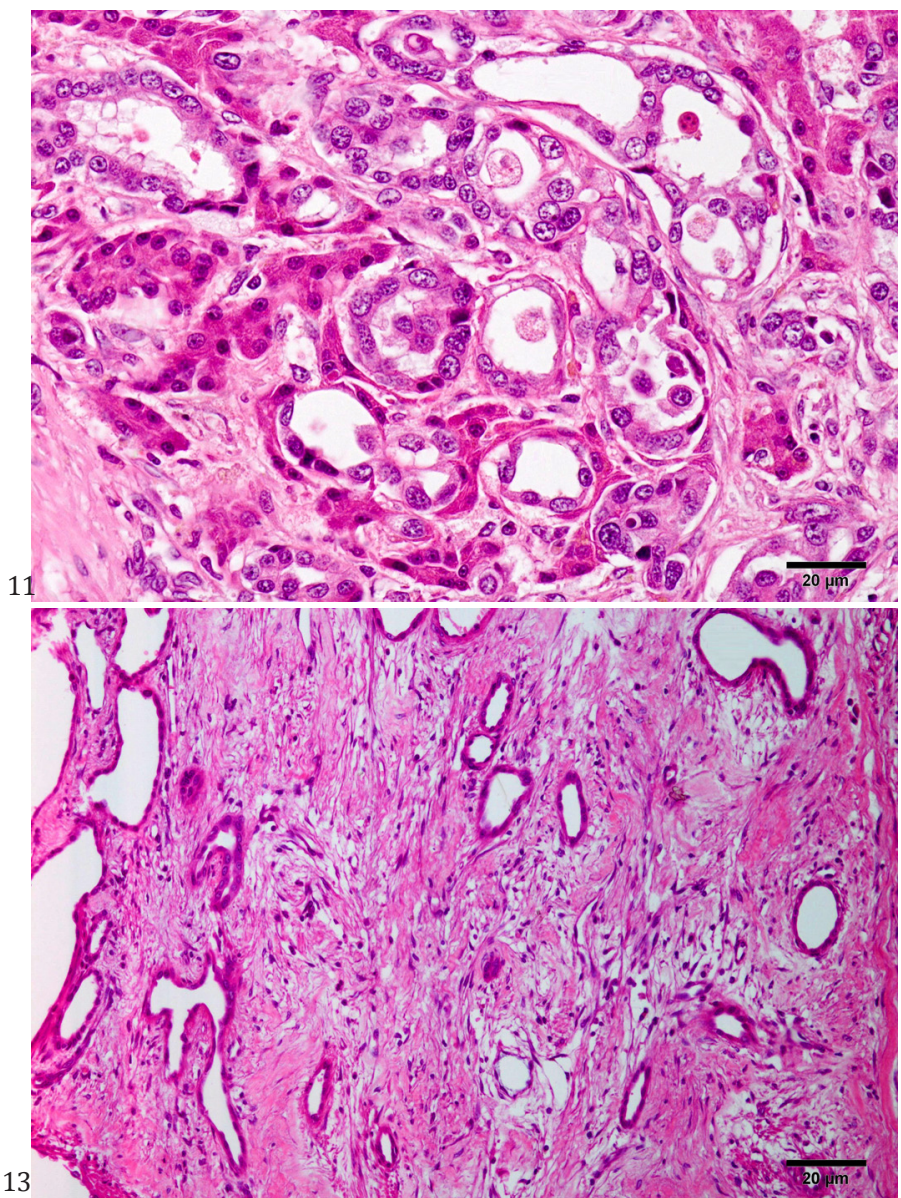

Fig.11. Fígado. Infiltrado neoplásico de células epiteliais que forma túbulos (padrão tubular) de diferentes tamanhos em um cão com colangiocarcinoma. HE, obj.20x.

Fig.13. Fígado. Tecido fibrovascular maduro que substitui o parênquima hepático e encerra alguns poucos túbulos neoplásicos em um cão com colangiocarcinoma. HE, obj.10x.

localizada no lobo lateral direito, firme, com cerca de $15 \mathrm{~cm}$ de diâmetro, e que tinha áreas vermelhas, amarelas, verdes e marrons entremeadas. Os múltiplos lóbulos que constituíam a massa variavam de tamanho e eram separados uns dos outros por septos de tecido conjuntivo fibroso. Não foram observadas metástases ou quaisquer alterações extra-hepáticas relacionadas a esse tumor.

\section{Achados histopatológicos (população com colangiocar- cinoma)}

Na histologia $(n=36)$, a maior parte dos colangiocarcinomas $(31 / 36[86,1 \%])$ foi caracterizada pela formação de túbulos de diferentes tamanhos (padrão tubular) (Fig.11). Apenas em alguns casos (5/36 [13,9\%]) não ocorreu formação de túbulos; nesses havia proliferação de células neoplásicas na forma de mantos (padrão sólido) (Fig.12). Alguns poucos casos $(3 / 36[8,3 \%])$ demonstravam grandes áreas císticas, que lembravam favos de mel (padrão cístico [cistadenocarcinomas biliares]), em meio à proliferação tubular.

0 estroma do tumor variou de escasso, no qual os feixes de tecido conjuntivo colagenoso eram quase imperceptíveis em meio às células neoplásicas, a esquirroso, no qual

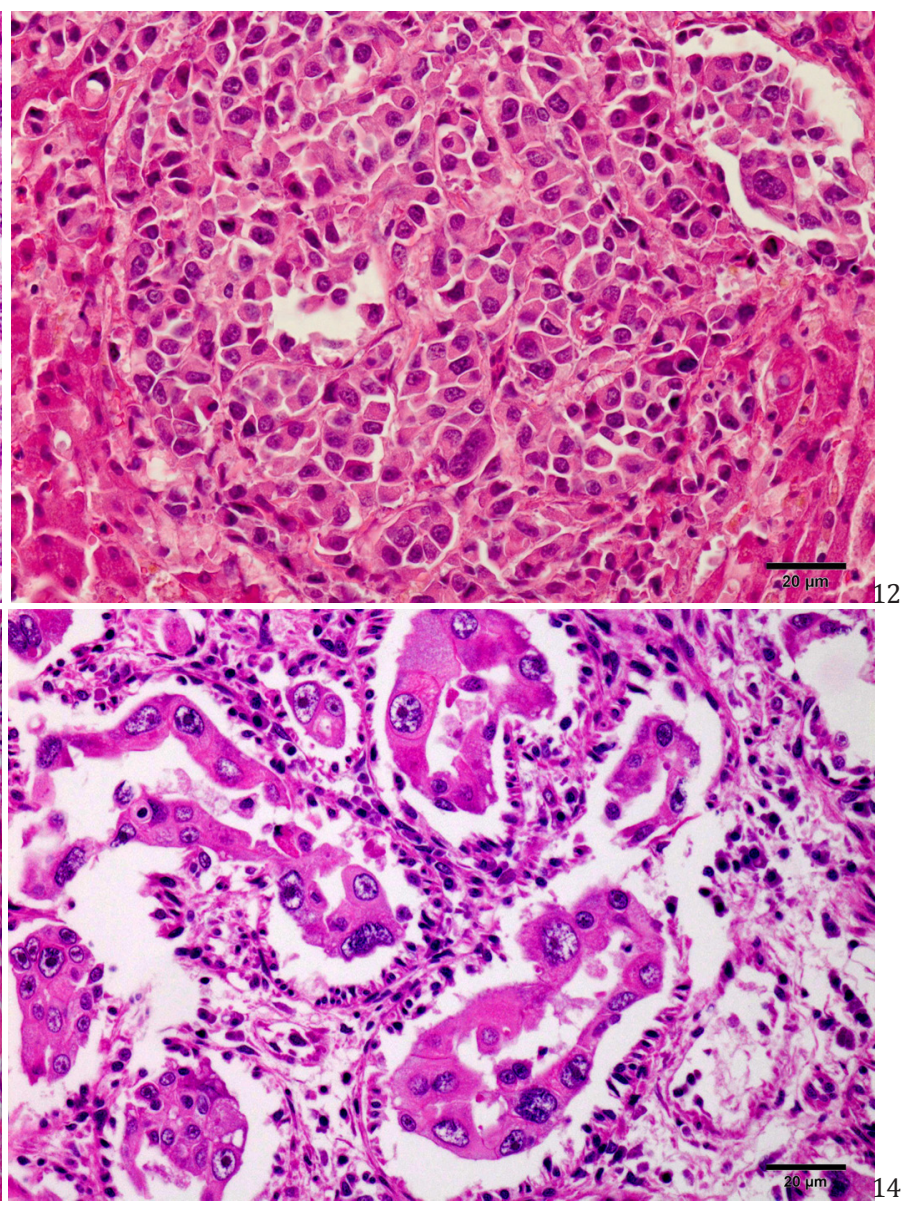

Fig.12. Fígado. Proliferação de células epiteliais na forma de um manto (padrão sólido) que infiltra e substitui os cordões de hepatócitos em um cão com colangiocarcinoma. HE, obj.20x.

Fig.14. Fígado. Marcada atipia celular. Note a anisocitose, a anisocariose e os nucléolos conspícuos em um cão com colangiocarcinoma. HE, obj.20x.

era tão abundante que chegava a isolar grupos de células em pequenas ilhas (Fig.13). De acordo com essa classificação, a maioria dos tumores $(25 / 36$ [69,4\%]) tinha estroma escasso e a minoria $(11 / 36[30,6 \%])$ tinha estroma abundante.

A atipia e pleomorfismo celular foram observados em cerca de um terço dos casos (13/36 [36,1\%]) (Fig.14) e o grau de mitoses predominante foi baixo $(33 / 36$ [91,7\%]), já tumores de alto grau foram bem menos comuns (3/36 [8,3\%]). Invasão de vasos linfáticos (Fig.15) foi uma característica proeminente, vista em cerca de dois terços dos casos $(23 / 36$ [63,9\%]). Essa invasão era muitas vezes evidente a ponto de formar grupos sólidos de células neoplásicas no interior desses vasos, que ocasionalmente eram vistas na forma de pequenos túbulos. Áreas com quantidades variáveis de necrose $(24 / 36[66,7 \%])$, hemorragia $(8 / 36$ $[22,2 \%])$, inflamação $(7 / 36[19,4 \%])$ e presença de muco (4/36 [11,1\%]) (Fig.16) também foram observadas. Em pelo menos um quarto dos casos (9/36 [25\%]) havia áreas aparentemente benignas em meio ao infiltrado neoplásico maligno. Essas áreas eram formadas por células neoplásicas bem diferenciadas, monomórficas e arranjadas em 


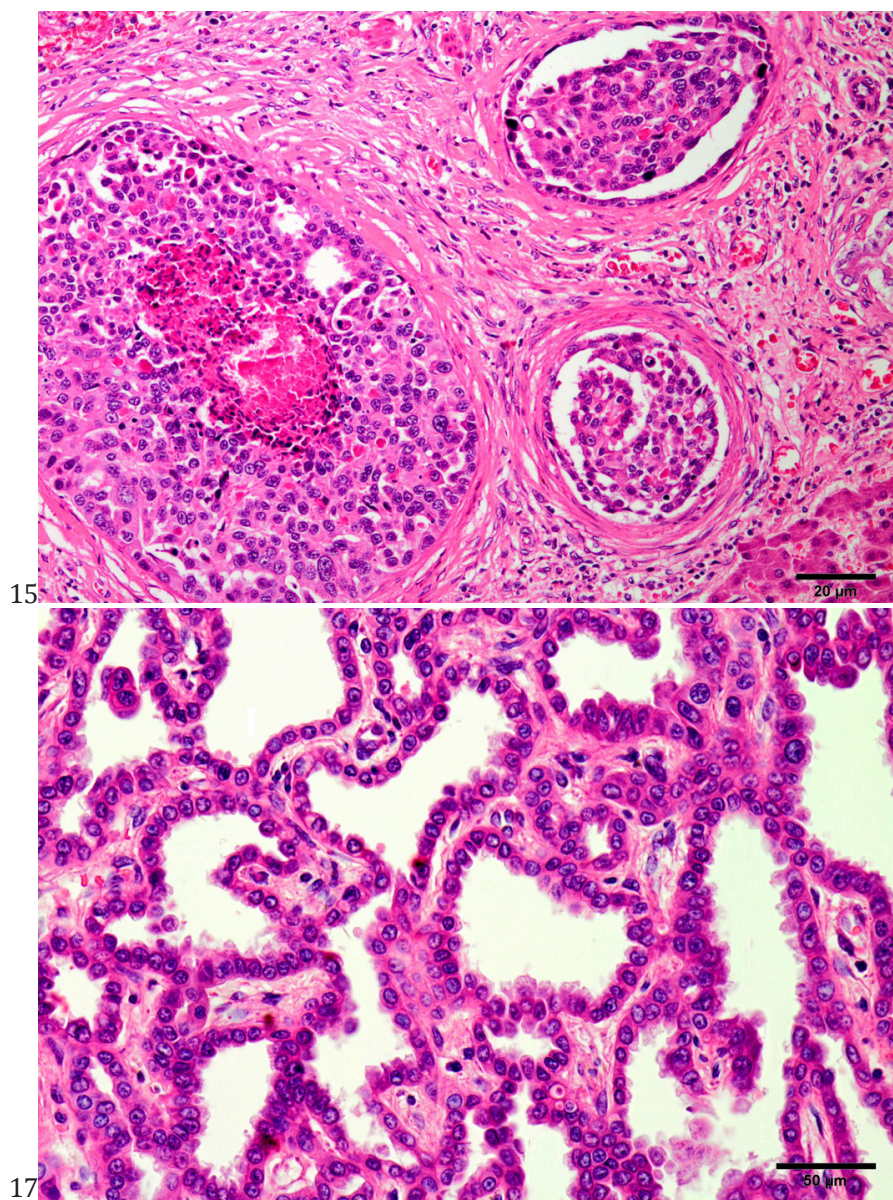

Fig.15. Fígado. Múltiplos vasos linfáticos invadidos e parcialmente obliterados por células epiteliais neoplásicas, alguns das quais se agrupam na forma de túbulos em um cão com colangiocarcinoma. HE, obj.20x.

Fig.17. Fígado. Múltiplos túbulos neoplásicos distendidos e perfeitamente diferenciados, uma marca registrada dos colangiomas, em um cão com colangiocarcinoma. HE, obj.20x.

túbulos regulares de diferentes tamanhos (Fig.17). Em um caso $(1 / 36[2,8 \%])$, o parênquima hepático adjacente ao neoplasma apresentava critérios que permitiram um diagnóstico de "cirrose hepática". Esses achados histológicos incluíam: fibrose periportal acentuada associada à formação de pontes de colágeno entre os espaços porta (fibrose em ponte) e nódulos constituídos de hepatócitos bem diferenciados e sem espaços-porta (nódulos de regeneração hepatocelular).

\section{Achados histopatológicos (população com carcinoma hepatocelular)}

Na histologia $(n=9)$, todos os carcinomas hepatocelulares tinham arranjo celular clássico, dos quais cerca da metade (5/9 [55,6\%]) foi considerado como trabecular e outra metade $(4 / 9[44,4 \%])$ como sólido. Os tumores trabeculares eram constituídos de múltiplos lóbulos formados por células bem diferenciadas e arranjadas em trabéculas com duas a 15 camadas de células (Fig.18). Nenhum carcinoma hepatocelular classificado como trabecular apresentou atipia e apenas um $(1 / 9[11,1 \%])$ demonstrou pleomorfismo. Os tumores sólidos caracterizavam-se por serem desorga-

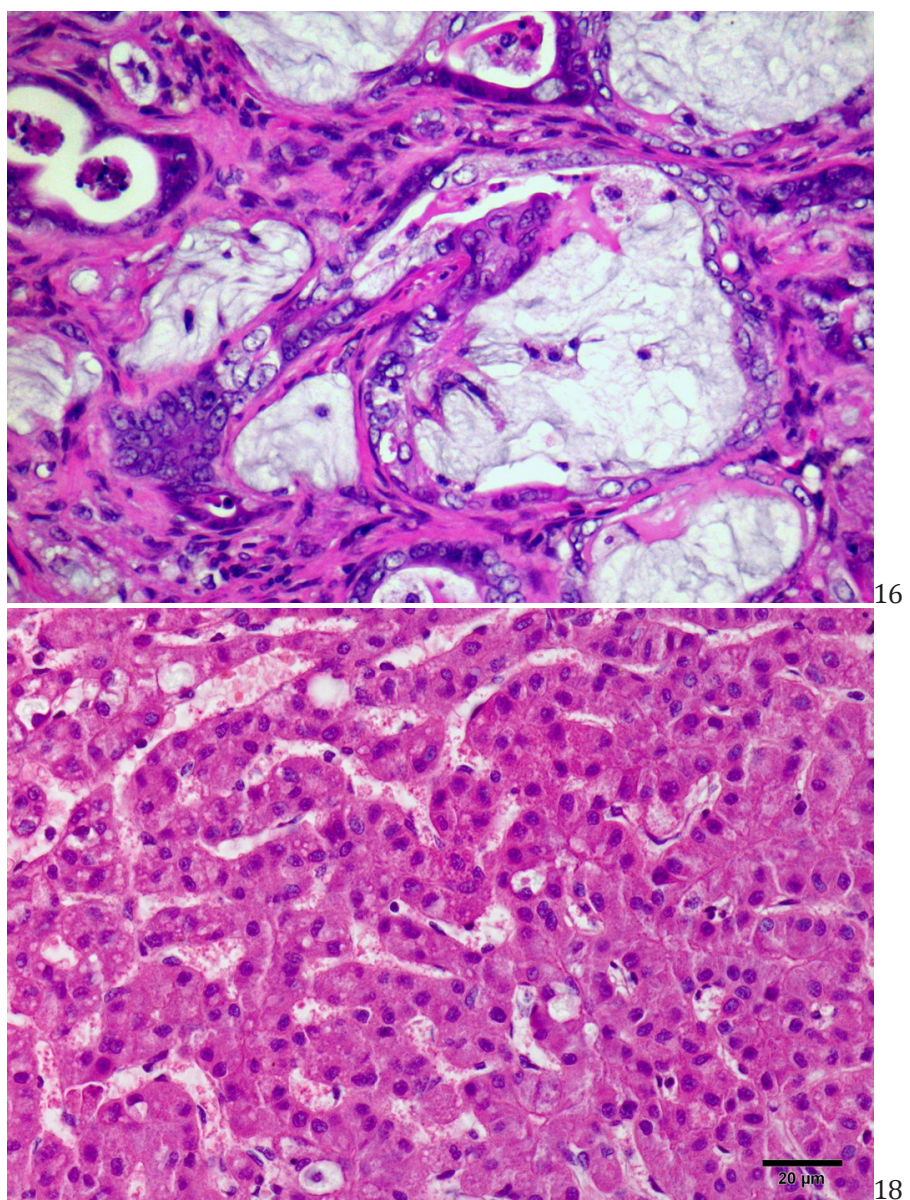

Fig.16. Fígado. Túbulos neoplásicos repletos de muco em um cão com colangiocarcinoma. HE, obj.20x.

Fig.18. Fígado. Infiltrado neoplásico constituído de hepatócitos bem diferenciados e arranjados em trabéculas (padrão trabecular) em um cão com carcinoma hepatocelular. HE, obj.20x.

nizados, ou seja, não formarem trabéculas, e eram compostos por células dispostas em mantos sólidos (Fig.19). Todos eles eram marcadamente pleomórficos e tinham quantidades variáveis de células que demonstravam intensa atipia (Fig.20), incluindo a ocorrência de células gigantes, por vezes multinucleadas, com núcleos grandes (cariomegalia) e nucléolos proeminentes.

Em todos os casos (9/9 [100\%]) havia quantidade escassa de estroma, constituído de finos septos de tecido conjuntivo fibrovascular, baixo grau de mitoses e ausência de invasão linfática e de áreas aparentemente benignas em meio ao infiltrado neoplásico maligno. Outros achados histológicos incluíram: necrose e hemorragia $(6 / 9$ [66,7\%]), degeneração gordurosa $(4 / 9$ [44,4\%]), formação de espaços cavernosos repletos de sangue $(3 / 9$ [33,3\%]), hematopoiese extramedular $(3 / 9$ [33,3\%]) e infiltrado inflamatório supurativo $(1 / 9[11,1 \%])$.

\section{Achados histopatológicos (população com hepatoco- langiocarcinoma)}

$\mathrm{Na}$ histologia $(\mathrm{n}=1)$, o hepatocolangiocarcinoma era constituído de hepatócitos proliferados formando uma 
massa multilobulada, cujos lóbulos eram separados uns dos outros por finos septos de tecido conjuntivo fibroso. Esses hepatócitos estavam arranjados em trabéculas com uma a 17 camadas de células com graus variados de organização. Em meio à proliferação de hepatócitos, observava-se uma segunda população neoplásica, que formava túbulos em meio aos hepatócitos. Esses túbulos eram pequenos a médios, irregulares, repletos de muco e estavam isolados uns dos outros pelas trabéculas de hepatócitos neoplásicos ou por pequena quantidade de estroma fibrovascular. 0 índice mitótico era baixo e nenhum dos outros critérios avaliados foi observado.

\section{Achados imuno-histoquímicos (população com colan- giocarcinoma)}

$\mathrm{Na}$ imuno-histoquímica $(\mathrm{n}=36)$, a maioria $(23 / 36$ [63,9\%]) dos colangiocarcinomas demonstrou imunomarcação para CK7 (Fig.21) e nenhum imunomarcou para Hep Par 1. Essa positividade foi altamente heterogênea, tanto em intensidade quanto em número de células

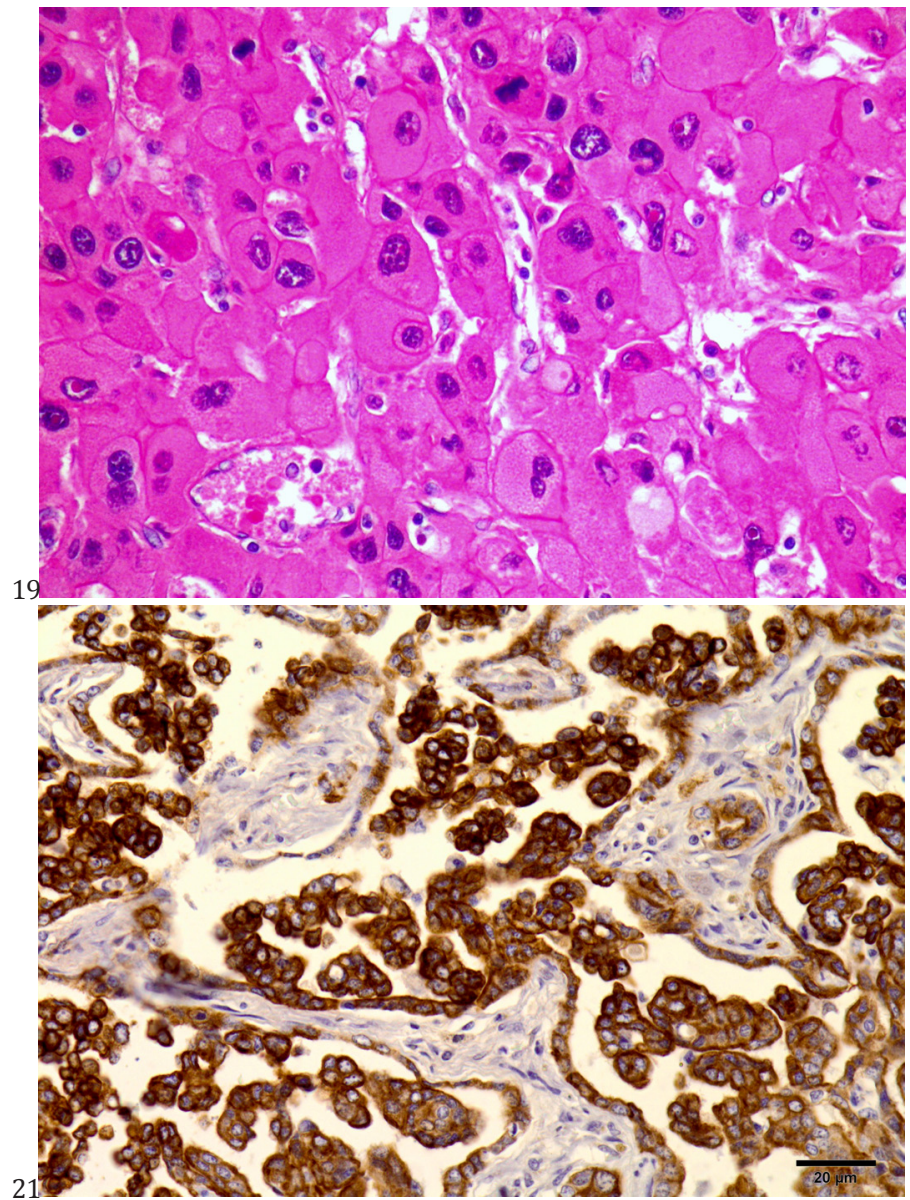

Fig.19. Fígado. Infiltrado neoplásico constituído de hepatócitos menos diferenciados e com distribuição mais densa (padrão sólido) em um cão com carcinoma hepatocelular. HE, obj.20x.

Fig.21. Fígado. A imunorreatividade para CK7 é observada na forma de uma marcação citoplasmática difusa das células neoplásicas que formam os túbulos nesse cão com colangiocarcinoma. Imuno-histoquímica (sistema de amplificação por polímero-HRP [não biotinilado]), obj.20x. imunomarcadas, inclusive em um mesmo corte. A imunomarcação da maioria das células neoplásicas era mais intensa no citoplasma próximo à membrana plasmática, principalmente na porção apical (Fig.22). A minoria das células neoplásicas demonstrava imunomarcação citoplasmática densa e difusa, dificultando a visualização do núcleo. Com base nesses achados, a imunomarcação foi dividida quanto à intensidade em: fraca $(5 / 36[13,9 \%])$, moderada (3/36 [8,3\%]), intensa (8/36 [22,2\%]) e muito intensa $(7 / 36[19,4 \%])$. Essa heterogeneidade também foi observada nos controles internos (ductos biliares normais) positivos. Dos casos sem imunomarcação para CK7 $(13 / 36[36,1 \%])$, cerca da metade $(7 / 13[53,8 \%])$ teve os seus controles internos (ductos biliares normais) negativos enquanto cerca da outra metade $(6 / 13[46,2 \%])$ teve os seus controles internos positivos. Dos casos em que as células neoplásicas e dos ductos biliares normais falharam em imunomarcar, quase todos (6/7 [85,7\%]) estavam autolisados. Dos casos em que as células neoplásicas falharam em imunomarcar, mas o controle interno

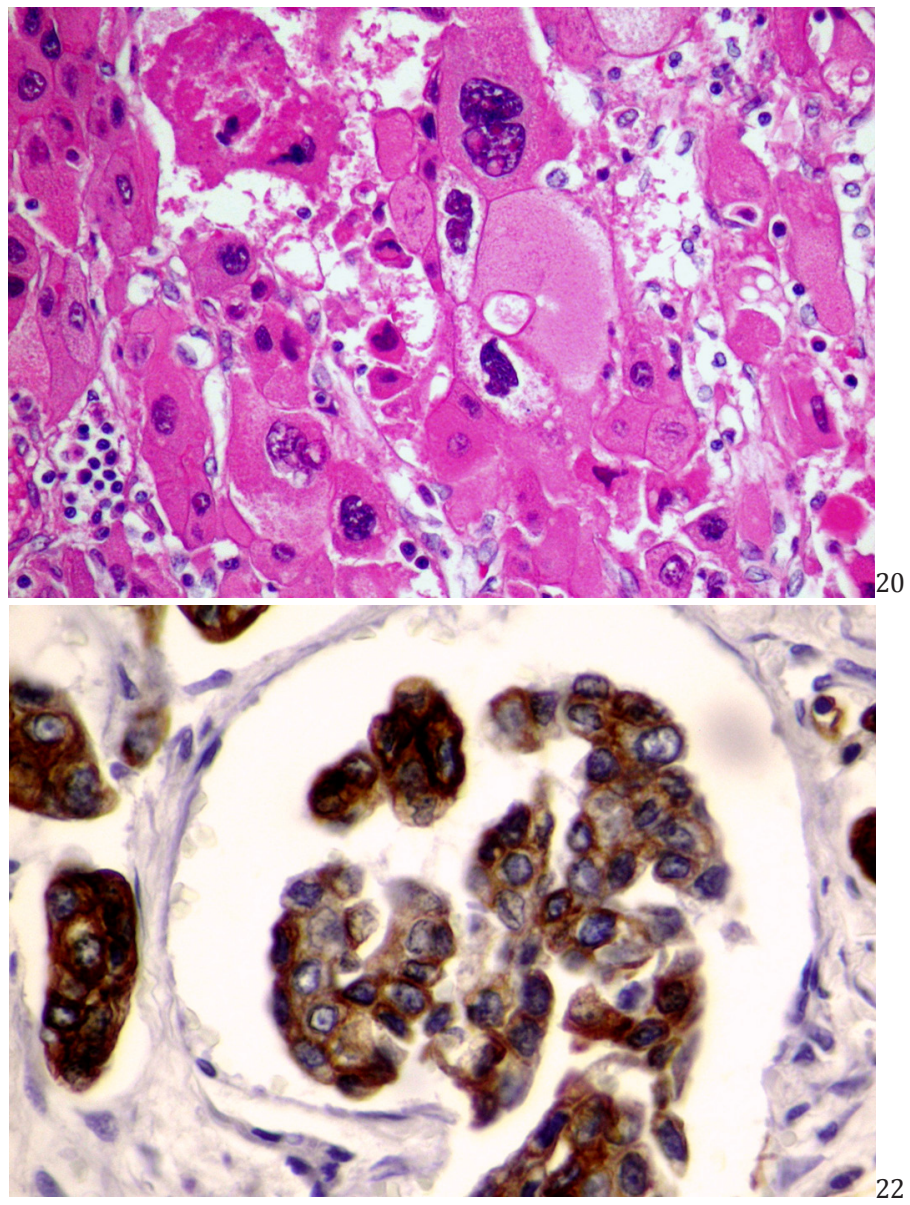

Fig.20. Fígado. Marcada atipia celular. Note a célula binucleada, a anisocitose, a anisocariose, os nucléolos conspícuos e as pseudo-inclusões de citoplasma no núcleo de um dos hepatócitos neoplásicos em um cão com carcinoma hepatocelular. HE, obj.40x.

Fig.22. Fígado. A marcação para CK7 pode ser mais bem visualizada no citoplasma apical próximo à membrana plasmática desse cão com colangiocarcinoma. Imuno-histoquímica (sistema de amplificação por polímero-HRP [não biotinilado]), obj.40x. 


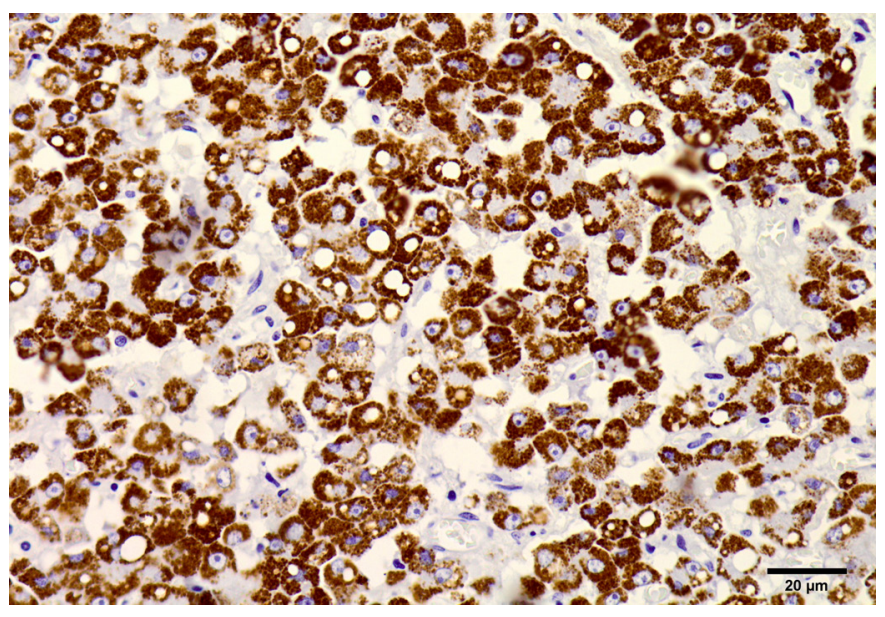

Fig.23. Fígado. A imunorreatividade para Hep Par 1 é forte e homogênea, o que facilitou muito o diagnóstico do carcinoma hepatocelular nos cães. Imuno-histoquímica (sistema de amplificação por polímero-HRP [não biotinilado]), obj.20x.

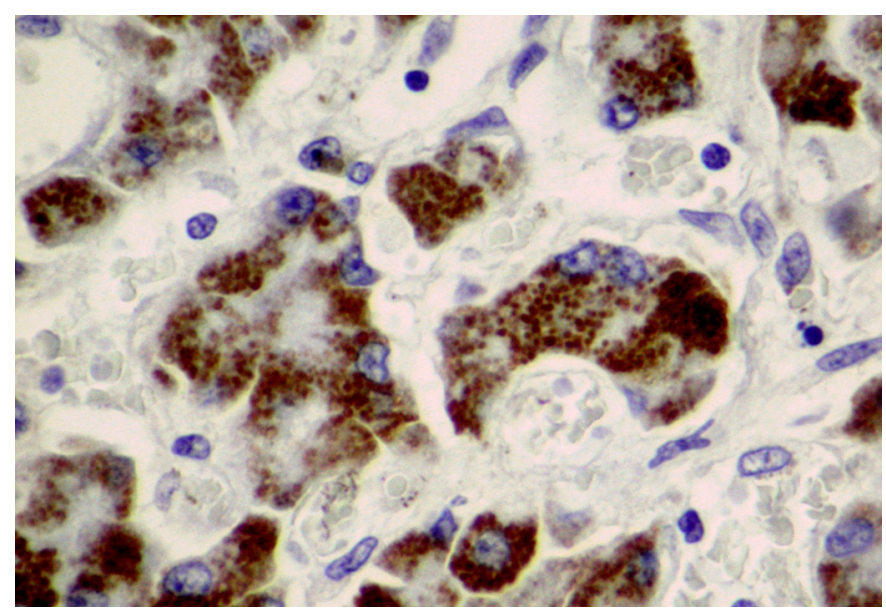

Fig.24. Fígado. A marcação para Hep Par 1 pode ser mais bem visualizada difusamente no citoplasma dos hepatócitos neoplásicos desse cão com carcinoma hepatocelular. Imuno-histoquímica (sistema de amplificação por polímero-HRP [não biotinilado]), obj.40x.

foi positivo, apenas um (1/6 [16,7\%]) demonstrou atipia celular.

\section{Achados imuno-histoquímicos (população com carci- noma hepatocelular)}

Na imuno-histoquímica ( $\mathrm{n}=9$ ), a maioria (5/9 [55,6\%]) dos carcinomas hepatocelulares demonstrou imunomarcação para Hep Par 1 (Fig.23) e nenhum imunomarcou para CK7. Essa positividade foi homogênea, com intensidade e número de células imunomarcadas muito semelhantes entre várias regiões do mesmo tumor e entre tumores diferentes, o que facilitava muito sua visualização. A imunomarcação das células neoplásicas era citoplasmática, difusa e granular (Fig.24). Quanto à intensidade, a imunomarcação foi dividida em: moderada (3/9 [33,3\%]), intensa (1/9 $[11,1 \%])$ e muito intensa $(1 / 9[11,1 \%])$. Essa homogeneidade também foi observada nos controles internos (hepatócitos normais) positivos. Dos casos sem imunomarcação para Hep Par (4/9 [44,4\%]), apenas um (1/9 [11,1\%]) teve seu controle interno (hepatócitos normais) negativo enquanto os outros $(3 / 9[33,3 \%])$ tiveram os seus controles internos positivos. Esse caso em que as células neoplásicas e os hepatócitos normais falharam em imunomarcar estava autolisado. Nos três casos em que as células neoplásicas falharam em imunomarcar, mas o controle interno foi positivo, havia atipia celular.

\section{Achados imuno-histoquímicos (população com hepa- tocolangiocarcinoma)}

Na imuno-histoquímica $(\mathrm{n}=1)$, o componente referente ao carcinoma hepatocelular demonstrou uma muito intensa imunomarcação para Hep Par 1, mas não para CK7. Essa positividade foi idêntica àquela descrita previamente para os carcinomas hepatocelulares. 0 componente referente ao colangiocarcinoma não demonstrou imunomarcação nem para CK7 nem para Hep Par 1.

\section{DISCUSSÃO}

Há poucos dados a respeito da real prevalência de tumores hepáticos em animais, principalmente quando comparamos essa situação à medicina humana (Crawford 1999, Cullen \& Popp 2002, Jemal et al. 2011). Por esse motivo, revisar a prevalência de THMP em cães é difícil, principalmente porque os trabalhos publicados (Strombeck 1978, Patnaik et al. 1980, Trigo et al. 1982, Bastianello 1983) avaliam parâmetros diferentes uns dos outros, tornando complicado comparar seus resultados. Apesar disso, a maior parte da literatura (Strombeck 1978, Patnaik et al. 1980, Bastianello 1983) considera os THMP como incomuns em cães, pois correspondem a menos de $1 \%$ dos tumores nessa espécie (Bastianello 1983), uma prevalência muito menor do que aquela encontrada por nós $(7,8 \%$ do total de cães que morreram por tumores em geral).

Outra diferença significativa que foi observada entre os nossos resultados e os dados já publicados na literatura é a percentagem de THMP em relação ao total de tumores de fígado. Segundo um estudo realizado no Reino Unido (Trigo et al. 1982), e que guia a maioria dos autores (Cullen \& Popp 2002, Head et al. 2003, Stalker \& Hayes 2007), apenas $21 \%$ dos cânceres de fígado são primários, uma prevalência bem mais baixa do que a encontrada por nós $33,5 \%$ do total de cães que morreram por tumores hepáticos) e por Messow (1952) (58\% do total de cães que morreram por tumores hepáticos). Apesar de existirem poucos trabalhos que apresentem parâmetros passíveis de serem comparados aos nossos resultados, a maioria dos autores concorda que THMP são incomuns e representam apenas uma pequena parcela das necropsias e dos neoplasmas diagnosticados em cães (Strombeck 1978, Trigo et al. 1982, Bastianello 1983, Cullen \& Popp 2002, Stalker \& Hayes 2007, Cullen \& Brown 2012). Em contrapartida, para esses mesmos autores, tumores secundários (metastáticos e multicêntricos) acometem o fígado mais frequentemente. Os resultados por nós descritos demonstram que na Região Central do RS há uma prevalência muito alta de THMP, o que faz deles uma causa bem mais comum de morte por tumores do que aquela vista em qualquer outra região do mundo em que estudos mais recentes já foram conduzidos 
e, consequentemente, diminui muito a relação entre tumores primários e secundários do fígado.

O carcinoma hepatocelular e o colangiocarcinoma são os THMP mais comuns em cães, representando $70 \%$ a $91 \%$ desses tumores nessa espécie (Strombeck 1978, Patnaik et al. 1980, Trigo et al. 1982, Cullen \& Popp 2002). Baseado em um número considerável de estudos (Strombeck 1978, Patnaik et al. 1980, 1981a, 1981b, Trigo et al. 1982, Ramos-Vara et al. 2001), a maioria dos autores (Ponomarkov \& Mackey 1976, Cullen \& Popp 2002, Head et al. 2003, Stalker \& Hayes 2007) concorda que o carcinoma hepatocelular é o câncer hepático primário mais diagnosticado em cães. Em alguns desses estudos (Patnaik et al. 1980, Ramos-Vara et al. 2001), os colangiocarcinomas representam apenas uma pequena parcela dos THMP, ficando muito atrás dos carcinomas hepatocelulares. Patnaik et al. (1980) obtiveram uma relação de cerca de $71 \%$ versus $29 \%$ para carcinomas hepatocelulares e colangiocarcinomas, respectivamente. Apesar disso, alguns autores (Trigo et al. 1982) demonstram uma diferença menor na relação entre esses dois tumores (58\% versus $42 \%$ ). Apenas um pequeno número de estudos (Messow 1952, Rooney 1959, Bastianello 1983), todos eles muito antigos, aponta o colangiocarcinoma como o câncer hepático mais prevalente em cães. Esses tumores chegaram a representar cerca de $87 \%, 69 \%$ e $57 \%$ dos THMP nos estudos de Messow (1952), Rooney (1959) e Bastianello (1983), realizados na Alemanha, Suécia e na África do Sul (esse último conduzido entre 1935 e 1974), respectivamente. Semelhantemente, em nossa rotina, a proporção de colangiocarcinomas para carcinomas hepatocelulares foi de $4: 1$ ( $80 \%$ versus $20 \%$ ). 0 grande número de colangiocarcinomas aqui diagnosticados causa uma elevação na prevalência dos THMP do LPV-UFSM, o que explica o fato de $7,8 \%$ de todos os tumores de cães corresponderem a THMP. Além disso, o grande número de colangiocarcinomas aqui diagnosticados altera a proporção de tumores malignos primários e secundários. Isso explica o fato de termos um número bastante significativo de tumores primários do fígado $(33,5 \%)$ quando comparado aos secundários $(66,5 \%)$.

Baseado em um número razoável de estudos prévios (Rooney 1959, Patnaik et al. 1981a, 1981b, Trigo et al. 1982), acredita-se não existir nenhum tipo de predisposição sexual ou racial para o desenvolvimento de câncer hepático em cães, entretanto, pelo menos um estudo anterior (Hayes et al. 1983) demonstrou risco relativo maior de fêmeas castradas e de cães da raça Labrador Retriever. Neste estudo, as proporções de cães SRD e de RP e de machos e fêmeas afetados por colangiocarcinomas e carcinomas hepatocelulares foram muito próximas às respectivas proporções na população geral de cães necropsiada no LPV-UFSM. Entretanto, quando os dados referentes a cada raça são comparados, nota-se que Boxers e Poodles contribuíram com $4,3 \%$ e $5,4 \%$ do total de necropsias no período avaliado e com $11,1 \%$ e $8,3 \%$ do total de colangiocarcinomas, respectivamente. Com exceção do estudo de Rooney (1959), o qual relatou um maior número de cães adultos acometidos por colangiocarcinoma, para a maioria dos autores, colangiocarcinomas (Patnaik et al. 1981a, Hayes et al. 1983) e carcinomas hepatocelulares (Rooney 1959, Patnaik et al. 1981b) afetam mais frequentemente cães acima de 10 anos de idade, ou seja, idosos. Apesar de cerca de um terço dos casos de colangiocarcinoma aqui descritos terem afetados adultos, semelhante ao observado por Rooney (1959), idosos representaram a grande maioria dos cães acometidos.

Segundo a maioria dos autores (Cullen \& Popp 2002, Head et al. 2003, Stalker \& Hayes 2007), colangiocarcinomas e carcinomas hepatocelulares têm aparência macroscópica distinta. Colangiocarcinomas ocorrem mais frequentemente sob a forma de múltiplos nódulos branco-amarelados que afetam todos os lobos hepáticos (Rooney 1959, Rehmtulla 1974, Patnaik et al. 1981a, Trigo et al. 1982). Essa apresentação, denominada "multinodular" (Head et al. 2003), foi observada em aproximadamente $83 \%$ dos colangiocarcinomas incluídos neste estudo. Diferentemente, carcinomas hepatocelulares ocorrem mais frequentemente como massas grandes e solitárias, que substituem completamente um lobo hepático (Mulligan 1949, Rooney 1959, Patnaik et al. 1981b, Trigo et al. 1982). Essa apresentação, denominada "massiva" (Head et al. 2003), foi vista em aproximadamente $44 \%$ dos carcinomas hepatocelulares incluídos neste estudo. Menos frequentemente (Patnaik et al. 1981a, Trigo et al. 1982), colangiocarcinomas podem ocorrer como uma única massa que substitui um lobo hepático, um padrão massivo muito semelhante ao descrito para os carcinomas hepatocelulares. Essa apresentação foi observada por nós em cerca de $17 \%$ dos colangiocarcinomas. Também menos frequentemente (Mulligan 1949, Rooney 1959, Patnaik et al. 1981b), carcinomas hepatocelulares podem ocorrer na forma de múltiplos nódulos que acometem vários ou todos os lobos hepáticos, um padrão nodular muito semelhante ao descrito para os colangiocarcinomas. Essa apresentação foi vista por nós em cerca de $44 \%$ dos carcinomas hepatocelulares.

A consistência firme e a coloração brancacenta, descritas em cerca de $31 \%$ e $53 \%$ dos nossos casos de colangiocarcinomas, respectivamente, são comentadas em outros estudos (Rehmtulla 1974, Patnaik et al. 1981a, Trigo et al. 1982) como características comuns e atribuídas à grande quantidade de estroma fibroso (Head et al. 2003). A ocorrência de depressão central ("nódulos umbilicados"), vista em cerca de 39\% dos nossos casos, é outra característica marcante dos colangiocarcinomas, e tem sido atribuída a necrose (Patnaik et al. 1981a, Trigo et al. 1982, Head et al. 2003). Colorações esverdeadas, geralmente associadas ao acúmulo de pigmento biliar, não foram observadas, e realmente não são descritas em colangiocarcinomas (Trigo et al. 1982), pois as células neoplásicas não contribuem com a produção da bile (Crawford 1999). Diferentemente dos colangiocarcinomas, carcinomas hepatocelulares são quase sempre pigmentados (marrons, vermelhos, amarelos, cinzentos ou esverdeados) (Mulligan 1949, Rooney 1959, Trigo et al. 1982), macios, amolecidos ou friáveis (Rooney 1959, Patnaik et al. 1981b, Trigo et al. 1982), colorações e consistências vistas em cerca de $33 \%$ dos casos deste estudo.

Colangiocarcinomas são considerados por muitos autores como os THMP mais metastáticos (Patnaik et al. 
1980, Trigo et al. 1982, Cullen \& Popp 2002). Metástases foram observadas à necropsia em cerca de $78 \%$ dos casos aqui descritos, um resultado semelhante ao descrito na literatura (77\% [Trigo et al. 1982] a 88\% [Patnaik et al. 1980]). Diferentemente dos colangiocarcinomas, carcinomas hepatocelulares são reconhecidos por serem menos metastáticos (Patnaik et al. 1981b, Trigo et al. 1982). Metástases foram observadas à necropsia em cerca de $33 \%$ dos casos aqui descritos, um resultado semelhante ao descrito na literatura (22\% [Trigo et al. 1982] a 61\% [Patnaik et al. 1981b]). Quanto aos órgãos afetados, nossos resultados confirmam o que ressaltam muitos autores (Rooney 1959, Rehmtulla 1974, Patnaik et al. 1981a, Trigo et al. 1982, Cullen \& Popp 2002), que embora colangiocarcinomas possam metastatizar virtualmente para qualquer órgão, acometem com maior frequência os pulmões, os linfonodos e o peritônio, ou seja, os mesmos órgãos classicamente afetados por metástases de carcinomas hepatocelulares. Nossos achados dão conta de que realmente pulmões (cerca de 53\% dos casos), linfonodos $50 \%$ dos casos) e cavidade abdominal (omento, mesentério e peritônio parietal) (cerca de 19\% dos casos) são os órgãos mais frequentemente acometidos por metástases de colangiocarcinomas, entretanto, o baixo número de casos de carcinomas hepatocelulares em que ocorreram metástases dificulta a discussão desse ponto.

Em cerca de $11 \%$ e $22 \%$ dos casos de carcinomas hepatocelulares e colangiocarcinomas, os padrões nodulares demonstravam pelo menos um lobo massivamente afetado. Se essa apresentação, que é interpretada por alguns autores (Rooney 1959, Patnaik et al. 1981a, Cullen \& Popp 2002, Head et al. 2003) como metastatização intra-hepática, for também assim interpretada, o fígado pode ser considerado como um dos órgãos mais afetados por metástases desses dois THMP.

Estudos mais antigos têm citado casos de cirrose hepática canina em associação com carcinomas hepatocelulares e colangiocarcinomas (Mulligan 1949, Ponomarkov \& Mackey 1976, Patnaik et al. 1980, Trigo et al. 1982). Nossos resultados apontam para uma associação muito baixa (cerca de $2 \%$ dos casos) entre essas condições. Em humanos, estima-se que $50 \%$ a $90 \%$ dos casos de carcinoma hepatocelular sejam associados à cirrose hepática (Jemal et al. 2011). Isso ocorre principalmente porque na maioria dos casos a cirrose é fator predisponente ao desenvolvimento do tumor (Crawford 1999). 0 fato de cirrose ser um achado incomum em cães com THMP sugere que talvez a etiologia e/ou a patogênese dos neoplasmas hepáticos nessa espécie seja diferente da de humanos (Patnaik et al. 1981b).

Segundo a literatura, as principais alterações extra-hepáticas relacionadas a THMP incluem hemoperitônio (Rooney 1959), ascite (Rooney 1959, Patnaik et al. 1981a, 1981b) e icterícia (Rooney 1959, Rehmtulla 1974, Patnaik et al. 1981a, Trigo et al. 1982). Hemoperitônio ou hemotórax em decorrência da ruptura de tumores primários ou metastáticos, respectivamente, foi observado em cerca de $28 \%$ dos casos de colangiocarcinomas e cerca de $22 \%$ dos casos de carcinomas hepatocelulares. Ascite ou hidrotórax foi observado em cerca de $14 \%$ e $11 \%$ dos casos de colan- giocarcinomas, respectivamente, mas não em casos de carcinomas hepatocelulares. Tais acúmulos têm sido atribuídos principalmente ao aumento da pressão hidrostática intravascular (PHI) e, menos frequentemente, à insuficiência hepática crônica (Stalker \& Hayes, 2007). Icterícia foi vista por nós em aproximadamente $22 \%$ dos casos e essa prevalência foi igual para colangiocarcinomas e carcinomas hepatocelulares, um resultado distinto, pois a maioria dos autores (Rehmtulla 1974, Patnaik et al. 1981a, Trigo et al. 1982) ressalta que esse achado é mais frequente em casos de colangiocarcinoma. É possível que o baixo número de carcinomas hepatocelulares deste estudo tenha interferido nessa relação.

A aparência histológica dos carcinomas hepatocelulares e colangiocarcinomas varia consideravelmente de acordo com o grau de diferenciação das células neoplásicas e com o arranjo do tumor (Rooney 1959, Patnaik et al. 1981a, 1981b, Trigo et al. 1982). Colangiocarcinomas bem diferenciados têm suas células arranjadas em um padrão tubular. À medida que se tornam pouco diferenciados, passam a apresentar um arranjo sólido, até que a presença de células organizadas em túbulos se torna incomum (Ponomarkov \& Mackey 1976, Cullen \& Popp 2002, Head et al. 2003). Dos tumores incluídos neste estudo, cerca de $86 \%$ tinham arranjo tubular, enquanto cerca de $14 \%$ tinham arranjo sólido. Embora os colangiocarcinomas com padrão tubular possam ser mais comuns (Patnaik et al. 1981a), tumores com padrão predominantemente sólido ocasionalmente prevalecem (Rooney 1959) e podem ser um desafio ao diagnóstico com base apenas na histologia.

A classificação histológica mais utilizada para carcinomas hepatocelulares inclui os padrões trabecular, adenoide e sólido (Head et al. 2003) ou combinações desses (Patnaik et al. 1981b). Tumores trabeculares são os que mais se assemelham ao tecido hepático normal, enquanto tumores sólidos são frequentemente pouco diferenciados (Ponomarkov \& Mackey 1976, Cullen \& Popp 2002). Para a maioria dos autores (Mulligan 1949, Rooney 1959, Patnaik et al. 1981b, Trigo et al. 1982), o padrão trabecular é o mais comum em cães, à semelhança do que foi observado por nós.

Cerca de $70 \%$ e $100 \%$ dos colangiocarcinomas e carcinomas hepatocelulares, respectivamente, demonstram padrão estromal escasso. Esses resultados são semelhantes ao que foi descrito na literatura para carcinomas hepatocelulares por vários autores (Rooney 1959, Patnaik et al. 1981b, Trigo et al. 1982) e embora colangiocarcinomas sejam frequentemente reconhecidos como neoplasmas esquirrosos, as principais referências acerca do assunto (Ponomarkov \&Mackey 1976, Cullen \& Popp 2002, Head et al. 2003) apontam para variações na quantidade de estroma.

0 grau de pleomorfismo e a atipia celular dos colangiocarcinomas e dos carcinomas hepatocelulares podem variar de acordo com o arranjo e com o grau de diferenciação, uma vez que tumores sólidos e, portanto, pouco diferenciados, geralmente têm alto grau de atipia e pleomorfismo quando comparados aos tumores tubulares (para colangiocarcinomas) e trabeculares ou adenoides (para carcinomas hepatocelulares) (Rooney 1959, Patnaik et al. 1981b, Trigo et al. 1982, Cullen \& Popp 2002, Head et al. 2003). Todos os 
carcinomas hepatocelulares incluídos neste estudo e classificados como "sólidos" tiveram pleomorfismo e atipia presentes, enquanto os demais, classificados como "trabeculares", não apresentaram tais critérios. Diferentemente, entre os colangiocarcinomas incluídos neste estudo, apenas 20\% dos tumores classificados como sólidos tinha indícios de atipia e pleomorfismo, enquanto cerca de $40 \%$ dos tumores tubulares apresentaram tais critérios. Esses achados nos permitem inferir que há uma aparente correlação entre a presença de atipia/pleomorfismo e a subclassificação histológica dos carcinomas hepatocelulares, uma vez que esses dois critérios estavam presentes em todos os tumores sólidos e ausentes nos demais tumores, entretanto, tal correlação não pôde ser observada nos colangiocarcinomas.

Com base em estudos anteriores (Patnaik et al. 1981a, Trigo et al. 1982), alguns autores (Cullen \& Popp 2002, Head et al. 2003) afirmam que a abundância de figuras mitóticas é uma característica típica de colangiocarcinomas, e que, em razão disso, a avaliação do grau de mitoses poderia auxiliar na diferenciação entre colangiocarcinomas e carcinomas hepatocelulares. Todos os carcinomas hepatocelulares incluídos neste estudo tinham baixo grau de mitoses, inclusive os tumores menos diferenciados. Em contrapartida, o baixo grau de mitoses também foi observado na grande maioria (cerca de 92\%) dos colangiocarcinomas. Com base em nossos achados, podemos deduzir que o grau de mitoses não é um critério confiável para diferenciar carcinoma hepatocelular de colangiocarcinoma.

A invasão de vasos linfáticos pelas células neoplásicas é mencionada apenas em alguns estudos acerca de colangiocarcinomas (Rooney 1959), embora o típico "padrão de crescimento invasivo" seja citado por vários autores (Cullen \& Popp 2002, Head et al. 2003, Stalker \& Hayes 2007). Em contrapartida, a característica de invasão parece ser menos pronunciada em carcinomas hepatocelulares (Cullen \& Popp 2002). Alguns autores (Cullen \& Popp 2002) relacionam o comportamento invasivo de colangiocarcinomas a sua marcada capacidade de metastatizar, principalmente quando comparado aos menores índices de metástases de carcinomas hepatocelulares. Dos colangiocarcinomas incluídos neste estudo, cerca de $64 \%$ demonstraram invasão de vasos linfáticos, enquanto nenhum carcinoma hepatocelular demonstrou essa mesma característica. De todos os casos de colangiocarcinomas que tinham invasão de vasos linfáticos na histologia, cerca de $83 \%$ tinham metástases extra-hepáticas. Com base nisso, podemos depreender que a visualização de invasão linfática na histologia está fortemente relacionada à ocorrência de metástases, embora a ausência deste critério histológico não descarte a possibilidade de metastatização, uma vez que, mesmo sem invasão linfática visível histologicamente, cerca de $33 \%$ dos carcinomas hepatocelulares metastatizaram, além de que 69\% dos colangiocarcinomas sem invasão linfática também tinham metástases.

A presença de áreas bem diferenciadas, e até aparentemente benignas, intercaladas com áreas pouco diferenciadas no mesmo tumor é ocasionalmente descrita para colangiocarcinomas (Rooney 1959, Patnaik et al. 1981a), e foi observada em $25 \%$ dos tumores aqui incluídos. Alguns autores (Patnaik et al. 1981a) interpretam essa mescla de áreas benignas e malignas como evidência de uma possível transformação neoplásica a partir de uma área benigna. No entanto, essa teoria não é comprovada (Head et al. 2003).

0 uso de Hep Par 1em THMP de cães é relatado apenas em um estudo (Ramos-Vara et al. 2001), o qual demonstrou alta sensibilidade (cerca de 93\%) para carcinomas hepatocelulares. Diferentemente, apenas $56 \%$ dos nossos casos de carcinomas hepatocelulares imunomarcaram. Esta grande diferença foi por nós atribuída a três fatores principais: 1) baixo número de carcinomas hepatocelulares, pois no estudo Ramos-Vara et al. (2001) o $n$ era 40; 2) presença de tumores em avançado grau de autólise, uma vez que todos os tumores em "pobre estado de conservação" foram excluídos do estudo de Ramos-Vara et al. (2001); e 3) presença de pouca diferenciação celular. Dos quatro carcinomas incluídos neste estudo e negativos para Hep Par 1, três estavam em avançado grau de autólise e um demonstrou marcada atipia e pleomorfismo. Sabidamente, autólise é um fator que pode interferir na conformação dos epítopos teciduais, e, portanto, na eficácia da imuno-histoquímica (Goldstein \& Silverman 2002, Ramos-Vara 2005). Apesar de Ramos-Vara et al. (2001) não terem observado nenhuma relação entre os graus de diferenciação celular e a sensibilidade do Hep Par 1, esta relação é relatada em carcinomas hepatocelulares de humanos (Chan \&Yeh 2010). Com base nesses achados, podemos depreender que o uso de Hep Par 1 em tumores autolisados ou pouco diferenciados pode ter sua eficácia limitada.

0 uso de CKs em geral (Martín de las Mulas et al. 1995), incluindo CK7 (Espinosa de los Monteros 1999, Ramos-Vara et al. 2001), já foi aplicado em estudos de THMP de cães. Tais estudos com CK7 demonstraram uma sensibilidade que variou de 67\% (Espinosa de los Monteros 1999) a 77,7\% (Ramos-Vara et al. 2001) para colangiocarcinomas, semelhante à observada por nós (cerca de 64\%). A marcação para CK7 é definida por alguns autores (Ramos-Vara et al. 2001) como sendo "desigual" e "eventualmente focal", principalmente por apresentar um padrão heterogêneo, com algumas células e ductos fortemente marcados, e outros sem nenhuma marcação. Na maioria dos colangiocarcinomas incluídos neste estudo, a marcação para esse anticorpo foi muito semelhante à descrita por Ramos-Vara et al. 2001, tornando difícil a interpretação de algumas lâminas $(21,7 \%)$, nas quais havia apenas raras células imunomarcadas. Apesar disto, em $65 \%$ dos nossos casos considerados positivos, foi possível visualizar mais de $50 \%$ de células imunomarcadas, semelhante ao estudo de Ramos-Vara et al. (2001), em que esse índice foi de $71 \%$. Isto nos permite inferir que a maioria dos tumores positivos para CK7 é de fácil interpretação, visto que frequentemente a maioria das células desses tumores demonstra marcação positiva.

Em razão de alguns carcinomas extra-hepáticos demonstrarem marcação positiva para CK7 (Espinosa de los Monteros 1999) e, raramente, para Hep Par 1(Ramos-Vara et al. 2001), a interpretação da imunomarcação para esses dois anticorpos deve ser feita com cautela, uma vez que existe a possibilidade dos tumores positivos terem uma origem metastática ao invés de primária. Além disto, even- 
tualmente, alguns carcinomas hepáticos primários podem demonstrar padrões de marcação aberrantes para CK7 e Hep Par 1, como é o caso de carcinomas hepatocelulares positivos para ambos os anticorpos ou de colangiocarcinomas e carcinomas hepatocelulares negativos para CK7 e Hep Par 1, respectivamente (Ramos-Vara et al. 2001).

0 uso de controles internos foi de grande valia neste estudo, visto que eles nos possibilitaram diferenciar os casos em que houve falha na imunomarcação daqueles em que as células do tumor eram realmente negativas para o anticorpo. Eventuais variações no estado de conservação, no tempo de fixação e no processamento da amostra podem ocasionar falhas na imuno-histoquímica (Goldstein \& Silverman 2002, Ramos-Vara 2005), como foi observado nos sete casos incluídos neste estudo, que também tinham seus controles internos negativos. Diante do fato de que em quase todos esses casos (6/7 [85,6\%]) havia autólise acentuada, uma plausível explicação para essa negatividade é o péssimo estado de conservação das amostras. No único caso $(1 / 7$ [14,3\%]) em que não ocorreu autólise, é possível que tenha ocorrido exposição do tecido a temperaturas demasiadamente altas durante o processamento, o que reconhecidamente prejudica a conformação dos epítopos (Goldstein \& Silverman 2002). Infelizmente, esta última teoria não pode ser confirmada pelo fato de que alguns tumores deste estudo foram diagnosticados com base em tecidos processados há mais de 20 anos.

\section{CONCLUSÕES}

Os resultados apresentados demonstram a frequente ocorrência de casos de THMP em cães da Região Central do RS, Brasil, principalmente carcinomas e, dentre esses, especialmente colangiocarcinomas. Dentre os fatores epidemiológicos relacionados ao desenvolvimento desse tipo de neoplasma, a idade avançada é sem dúvida o principal fator predisponente.

Os achados anatomopatológicos demonstram que mais comumente os colangiocarcinomas ocorrem de forma multinodular enquanto os carcinomas hepatocelulares são principalmente massivos, entretanto, o patologista não deve surpreender-se se, histologicamente, isso não se confirmar, pois a chance de um THMP caracterizado por apresentar múltiplos nódulos ser um carcinoma hepatocelular não é pequena, bem como a de um THMP com apresentação massiva ser um colangiocarcinoma não é tão insignificante. Se outros critérios macroscópicos, como coloração e consistência, forem analisados conjuntamente, a chance de confirmação histológica com base na macroscopia será maior.

Colangiocarcinomas são altamente metastáticos, muito mais metastáticos do que carcinomas hepatocelulares, e os principais sítios de metastatização incluem pulmões, linfonodos e cavidade abdominal. Lesões extra-hepáticas são comuns em ambos os tumores e incluem principalmente hemoperitônio e icterícia.

Na histologia, colangiocarcinomas e carcinomas hepatocelulares apresentam principalmente padrão tubular e trabecular, respectivamente, mas tumores com padrão sólido não são incomuns e podem dificultar o diagnóstico se a imuno-histoquímica não estiver disponível. Nesses casos, critérios diferenciadores incluem principalmente invasão linfática e quantidade de estroma, mas não grau de mitose e atipia ou pleomorfismo.

A imuno-histoquímica é uma técnica complementar importante no diagnóstico dos THMP, entretanto, necessita ser utilizada de forma contextualizada, pois sua interpretação isolada pode dificultar o diagnóstico definitivo, visto que não é incomum a negatividade dos colangiocarcinomas para CK7 e dos carcinomas hepatocelulares para Hep Par 1. Assim, a interpretação desses resultados deve ser baseada não só na positividade de colangiocarcinomas e carcinomas hepatocelulares para os seus respectivos marcadores, mas também na negatividade desses tumores para um marcador não-específico para eles, ou seja, a negatividade de colangiocarcinomas para Hep Par 1 e de carcinomas hepatocelulares para CK7 também auxilia muito no diagnóstico definitivo.

Agradecimentos.- Mariana Martins Flores é bolsista do Conselho Nacional de Desenvolvimento Científico e Tecnológico (CNPq).

\section{REFERÊNCIAS}

Bastianello S.S. 1983. A survey on neoplasia in domestic species over a 40-year period from 1935 to 1974 in the Republic of South Africa. VI. Tumours occurring in dogs. Onderstepoort J. Vet. Res. 50(3):199-220.

Chan E.S. \& Yeh M.M. 2010. The use of immunohistochemistry in liver tumors. Clin. Liver Dis. 14(4):687-703.

Crawford J.M. 1999. 0 fígado e o trato biliar, p.759-808. In: Cotran R.S., Kumar V. \& Collins T. (Eds), Robbins - Patologia estrutural e funcional. $6^{\text {th }}$ ed. W.B. Saunders, Philadelphia.

Cullen J.M. \& Popp J.A. 2002. Tumors of the liver and gall blader, p.483508. In: Meuten D.J. (Ed.), Tumors in Domestic Animals. $4^{\text {th }}$ ed. Iowa State Press, Ames.

Cullen J.M. \& Brown D.L. 2012. Hepatobiliary system and exocrine pancreas, p.405-457. In: Zachary J.F. \& McGavin M.D. (Eds), Pathologic Basis of Veterinary Disease. $5^{\text {th }}$ ed. Elsevier, St Louis.

Espinosa de los Monteros A., Fernández A., Millán M.Y., Rodríguez F., Herráez P. \& De las Mulas J.M. 1999. Coordinate expression of cytokeratins 7 and 20 in feline and canine carcinomas. Vet. Pathol. 36(3):179-190.

Fighera R.A. 2008. Causas de morte e razões para eutanásia de cães. Tese de Doutorado em Medicina Veterinária, Curso de Pós-Graduação em Medicina Veterinária, Universidade Federal de Santa Maria, Santa Maria, RS. $172 p$.

Fighera R.A., Souza T.M., Silva M.C., Brum J.S., Graça D.L., Kommers G.D., Irigoyen L.F. \& Barros C.S.L. 2008. Causas de morte e razões para eutanásia de cães da mesorregião do centro ocidental rio-grandense (1965-2004). Pesq. Vet. Bras. 28(4):223-230.

Goldstein N.S. \& Silverman J.F. 2002. Immunohistochemistry of the gastrointestinal tract, pancreas, bile ducts, gallbladder, and liver, p.333-406. In: Dabbs D.J. (Ed.), Diagnostic Immunohistochemistry. Churchill Livingstone, Philadelphia.

Hayes H., Morin M.M. \& Rubenstein D.A. 1983. Canine biliary carcinoma: Epidemiological comparisons with man. J. Comp. Path. 93(1):99-107.

Head K.W., Cullen J.M., Dubielzig R.R., Else R.W., Misdrop W., Patnaik A.K., Tateyama S. \& van der Gaag I. 2003. Histological Classification of Tumors of the Alimentary System of Domestic Animals. Armed Forces Institute of Pathology, Washington, DC, p.119-130.

Inkelmann M.A., Kommers G.D., Fighera R.A., Irigoyen L.F., Barros C.S.L., Silveira I.P. \& Trost M.E. 2011. Neoplasmas do sistema urinário em 113 cães. Pesq. Vet. Bras. 31(11):1102-1107.

Jemal A., Bray F., Center M.M., Ferlay J., Ward E. \& Forman D. 2011. Global cancer statistics. Cancer J. Clin. 61:69-90. 
Martín de las Mulas J., Gómez-Villamandos J.C., Pérez J. \& Mozos E. 1995. Immunohistochemical evaluation of canine primary liver carcinomas: distribution of alpha-fetoprotein, carcinoembryonic antigen, keratin and vimentin. Res. Vet. Sci. 59(2):124-127.

Messow C. 1952. Die Lebertumoren unserer Haussäugetiere. Wissenschaftliche Zeitschrift der Humboldt-Universitätzu Berlin 2:121-152.

Meuten D.J. 2002. Tumors in Domestic Animals. $4^{\text {th }}$ ed. Iowa State Press, Ames. 788p.

Mulligan R.M. 1949. Primary liver-cell carcinoma (hepatoma) in the dog. Cancer Res. 9:76-81.

Oliveira Filho J.C., Kommers G.D., Masuda E.K., Marques B.M.F.P.P., Fighera R.A., Irigoyen L.F. \& Barros C.S.L. 2010. Estudo retrospectivo de 1.647 tumores mamários em cães. Pesq. Vet. Bras. 30(2):177-185.

Patnaik A.K., Hurvitz A.I. \& Lieberman P.H. 1980. Canine hepatic neoplasms: a clinicopathologic study. Vet. Pathol. 17(5):553-564.

Patnaik A.K., Hurvitz A.I., Lieberman P.H. \& Johnson G.F. 1981a. Canine bile duct carcinoma. Vet. Pathol. 18(4):439-444.

Patnaik A.K., Hurvitz A.I., Lieberman P.H. \& Johnson G.F. 1981b. Canine hepatocellular carcinoma. Vet. Pathol. 18(4):427-438.

Ponomarkov V. \& Mackey L.J. 1976. Tumours of the liver and biliary system. Bull. World Health Organ. 53(2):187-194.

Ramos-Vara J.A., Miller M.A. \& Johnson G.C. 2001. Immunohistochemical characterization of canine hyperplastic hepatic lesions and hepatocellu- lar and biliary neoplasms with monoclonal antibody hepatocyte paraffin 1 and a monoclonal antibody to cytokeratin 7. Vet. Pathol. 38(6):636-643.

Ramos-Vara J.A. 2005. Technical aspects of immunohistochemistry. Vet. Pathol. 42(4):405-426.

Rehmtulla A.J. 1974. Bile duct carcinoma in a dog. Can. Vet. J. 15(11):331334.

Rooney J.R. 1959. Liver carcinoma in the dog. Acta Pathol. 45(4):321330.

Shiga A., Shirota K. \& Enomoto M. 2001. Combined hepatocellular and cholangiocellular carcinoma in a dog. J. Vet. Med. Sci. 63(4):483-486.

Souza T.M., Fighera R.A., Irigoyen L.F. \& Barros C.S.L. 2006. Estudo retrospectivo de 761 tumores cutâneos em cães. Ciência Rural 36:555-560.

Stalker M.J. \& Hayes M.A. 2007. Liver and Biliary System, p.348-353. In: Maxie M.G. (Ed.), Jubb, Kennedy, and Palmer's Pathology of Domestic Animals: Vol.1, $5^{\text {th }}$ ed. Saunders Elsevier, Philadelphia.

Strombeck D.R. 1978. Clinicopathologic features of primary and metastatic neoplastic disease of the liver in dogs. J. Am. Vet. Med. Assoc. 173(3):267-269.

Trigo F.J., Thompson H., Breeze R.G. \& Nash A.S. 1982.The pathology of liver tumours in the dog. J Comp. Pathol. 92(1):21-39.

Trost M.E., Kommers G.D., Brown C.C., Barros C.S.L., Irigoyen L.F., Fighera R.A., Inkelmann M.A. \& Silva T.M. 2012. Primary bone neoplasm in dogs: 90 cases. Pesq. Vet. Bras. 32(12):1329-1335. 